\title{
Identifying and characterising large ramps in power output of offshore wind farms
}

\section{Article}

\section{Accepted Version}

Creative Commons: Attribution-Noncommercial-No Derivative Works 4.0

Drew, D. R., Barlow, J. F. and Coker, P. J. (2018) Identifying and characterising large ramps in power output of offshore wind farms. Renewable Energy, 127. pp. 195-203. ISSN 09601481 doi: https://doi.org/10.1016/j.renene.2018.04.064 Available at https://centaur.reading.ac.uk/76800/

It is advisable to refer to the publisher's version if you intend to cite from the work. See Guidance on citing.

To link to this article DOI: http://dx.doi.org/10.1016/j.renene.2018.04.064

Publisher: Elsevier

All outputs in CentAUR are protected by Intellectual Property Rights law, including copyright law. Copyright and IPR is retained by the creators or other copyright holders. Terms and conditions for use of this material are defined in the End User Agreement.

\section{www.reading.ac.uk/centaur}

\section{CentAUR}

Central Archive at the University of Reading

Reading's research outputs online 


\title{
1 Identifying and characterising large ramps in power output of 2 offshore wind farms
}

\author{
3 Daniel. R. Drew ${ }^{1} *$, Janet. F. Barlow ${ }^{1}$ and Phil. J. Coker ${ }^{2}$
}

$4 \quad 1$ Department of Meteorology, University of Reading, Reading, UK

52 School of Construction Management and Engineering, University of Reading, Reading, UK

$6 *$ Author to whom correspondence should be addressed; E-Mail: d.r.drew@reading.ac.uk;

7 Tel.: +44 (0)118378 7696

8

\begin{abstract}
Recently there has been a significant change in the distribution of wind farms in Great Britain with the construction of clusters of large offshore wind farms. These clusters can produce large ramping events (i.e. changes in power output) on temporal scales which are critical for managing the power system (30 minute, 60 minute and 4 hours). This study analyses generation data from the Thames Estuary cluster in conjunction with meteorological observations to determine the magnitude and frequency of ramping events and the meteorological mechanism.
\end{abstract}

Over a 4 hour time window, the extreme ramping events of the Thames Estuary cluster were caused by the passage of a cyclone and associated weather fronts. On shorter time scales, the largest ramping events over 30 minute and 60 minute time windows are not associated with the passage of fronts. They are caused by three main meteorological mechanisms; (1) very high wind speeds associated with a cyclone causing turbine cut-out (2) gusts associated with thunderstorms and (3) organised band of convection following a front. Despite clustering offshore capacity, the addition of offshore wind farms has increased the mean separation between capacity and therefore reduced the variability in nationally aggregated generation on high frequency time scales.

Keywords: wind; offshore; variability; ramping; extremes

\subsection{Introduction}

To meet ambitious carbon reduction targets, global renewable energy deployment has expanded dramatically. In the UK, the capacity of wind power has grown steadily from $2.9 \mathrm{GW}$ in 2008 to 17.9 GW by June 2017 [1]. Due to the increasing penetration of wind power, extreme wind power generation events are of growing concern. In particular, ramps in generation provide challenges for the transmission system operator who schedule reserve holding in advance and require long term strategies for system balancing [2]. Consequently, a number of studies have focused on understanding and improving the predictability of wind power ramping events $[3,4,5,6]$.

For the UK, Cannon et al. [7] used wind speed data derived from the MERRA reanalysis dataset to quantify the magnitude and frequency of nationally-aggregated wind generation ramping on time scales of 6 hours and greater based on the 2012 wind farm distribution. However, in recent years there has been a significant change in the distribution of wind farms in the Great Britain [8]. Since 2012, the capacity of offshore wind farms has increased from $2.4 \mathrm{GW}$ to $5.0 \mathrm{GW}$ with much of this capacity spread over a small number of very large wind farms located in clusters. For example, in the Thames Estuary alone there is approximately $1.7 \mathrm{GW}$ of capacity. Drew et al. [3] showed this has led to large 
regional ramps in generation on time scales of minutes to hours as local meteorological phenomena simultaneously impacts production in several large farms. Given the large capacity of the farms, these ramps can present a challenge in maintaining the balance between supply and demand on a national scale, particularly if they are not accurately forecasted.

The problem posed by local ramping events is expected to be exacerbated in the coming years, given the trend for clustering capacity in large offshore wind farms looks set to continue. The latest phase of offshore wind development in the UK, launched in 2009, identified 9 zones within which a number of individual wind farms could be located with a total capacity of over $30 \mathrm{GW}[9,10]$. Consequently, following the construction of the round 3 wind farms the majority of GB wind capacity would be located offshore in clusters of very large wind farms [11, 12].

To improve the performance of operational wind power forecasts there is an increasing need for a clear understanding of the meteorological features responsible for the extreme local ramping events [13]. For example, Trombe et al. [14] showed that high frequency ramping of large Danish offshore wind farms can be associated with heavy rainfall and therefore considered the scope for using data from the rainfall radar to adjust the forecast in real-time if necessary. This study investigates whether such an approach could be applied to ramping events in the Thames Estuary wind farms.

In addition to the problems posed by local ramping events, there are concerns that clustering capacity could lead to an increase in the variability of the nationally aggregated wind generation (i.e. a reversal of some of the smoothing benefits gained by the spatial dispersion of turbines). A number of studies have investigated the reduction in wind power variability due to geographical dispersion of turbines for single European countries. For example, Kubik et al. for Northern Ireland [15], Hurley and Watson for Ireland [16], Hasche for Germany and Ireland [17] and Giebel [18], Landberg [19], Buttler [20] and Huber et al. [21] considered the whole of Europe.

For the UK, Sinden [22] and Earl et al. [23] used wind speed data measured at Met Office surface stations to quantify the inter-annual, seasonal and diurnal variability of UK aggregated wind generation. However, these studies did not consider offshore sites and assumed the distribution of wind capacity matched the distribution of weather stations which can lead to large errors [24]. To address this problem, Cannon et al. [7] used wind speed data derived from the MERRA reanalysis dataset to determine the characteristics of wind power in Great Britain over a 33 year period. The study provides a detailed climatology of ramping on time scales of 6 hours and greater.

Using the approach outlined in Cannon et al. [7], Drew et al. [12] showed that the increased penetration of offshore wind farms has little impact on the ramping of GB-aggregated wind generation on time scales of greater than 6 hours. However, due to the resolution of the model, MERRA reanalysis data cannot be used to determine the high frequency GB-aggregated power swings (minutes to hours) or quantify the magnitude of wind power ramps at high spatial resolutions (below $300 \mathrm{~km}$ ), both of which are important considerations for managing the power system.

In the UK, the electricity market is managed in 30 minute windows, known as settlement periods. For each period, suppliers and generators contract electricity up to 1 hour prior to the delivery time, a cutoff time known as "gate closure". It is then the responsibility of the system operator (National Grid) to take any necessary actions in order to balance the grid within each settlement period. The electricity network in the UK is largely isolated with relatively few interconnectors to neighbouring countries and therefore there is a reliance on large conventional power plants to manage the system. However, these plants generally require a period of notice prior to generation to ramp up, generally assumed to 
be at least 4 hours. To manage the power system, it is therefore important to understand the possible ramps in power that could occur on time scales shorter than the ramp up time of a conventional power plant (4 hours), between gate closure and settlement period ( 1 hour) and from one settlement period to the next (30 minutes).

The aim of this study is to use a 30-minute averaged time series of wind power generation from a number of regions across Great Britain (GB) in 2014 to investigate how the increased penetration of clustered offshore wind capacity has affected the characteristics of generation at high spatial and temporal resolutions. The first section considers the impact on high frequency variability of wind generation on both a national and regional scale, particularly the magnitude of ramping in generation on time scales of less than 4 hours. The second section determines the meteorological causes of extreme regional ramping events using the Thames Estuary as a case study.

\subsection{Datasets and analysis methods}

One of the main challenges when investigating the variability of wind generation in the UK at high spatiotemporal resolutions is the limited availability of suitable data. Actual metered data from the individual wind farms is protected by commercial interests; therefore there is a reliance on nationally aggregated data. However, analysis using this data is unable to quantify the regional power swings or indicate how the variability has been affected by the change in wind farm distribution. Cradden et al. [24] used an hourly 11 year hindcast derived using the Weather Research and Forecasting model (WRF) at $3 \mathrm{~km}$ resolution to assess the variability of generation from 13 different regions in the UK.

This study introduces a new dataset which details the aggregated power output from four offshore clusters (Anglia, Cumbria, N.Wales and Thames) and five onshore regions; Argyll, Ayrshire, Central, Lothian and SSENW (see Figure 1) at 30 min resolution from $1^{\text {st }}$ January 2014 to $31^{\text {st }}$ December 2014 (see Table 1 and Figure 1). The total capacity across the 9 regions is $6.5 \mathrm{GW}$, which is approximately $70 \%$ of the total installed wind capacity of Great Britain.

A number of wind farms have been excluded from the analysis for two reasons (1) they the sole wind farm in a region therefore it was not possible to produce anonymous, aggregated generation data or (2) the data was not of sufficient quality. Despite the reduced number of wind farms, the dataset provides a good representation of the wind resource. For example, the GB-aggregated capacity factor for 2014 was calculated to be $31 \%$, which compares well to the figure of $30.2 \%$ for the full wind farm distribution [25].

\begin{tabular}{|l|l|l|l|}
\cline { 2 - 4 } \multicolumn{1}{c|}{} & $\begin{array}{l}\text { Mean } \\
\text { separation } \\
(\mathrm{km})\end{array}$ & $\begin{array}{l}\text { Number } \\
\text { of farms }\end{array}$ & $\begin{array}{l}\text { Capacity } \\
(\mathrm{GW})\end{array}$ \\
\hline Lothian & 17.3 & 5 & 0.44 \\
\hline N.Wales & $\mathbf{2 6 . 9}$ & $\mathbf{3}$ & $\mathbf{0 . 1 8}$ \\
\hline Cumbria & $\mathbf{3 0 . 7}$ & $\mathbf{5}$ & $\mathbf{1 . 1 7}$ \\
\hline Thames & $\mathbf{3 4 . 5}$ & $\mathbf{4}$ & $\mathbf{1 . 5 4}$ \\
\hline Anglia & $\mathbf{3 8 . 1}$ & $\mathbf{3}$ & $\mathbf{0 . 3 3}$ \\
\hline Central & 60.7 & 11 & 1.22 \\
\hline Ayrshire & 79.3 & 8 & 0.52 \\
\hline Argyll & 89.1 & 6 & 0.30 \\
\hline SSENW & 115.2 & 16 & 0.80 \\
\hline
\end{tabular}


Table 1 Details of the 4 offshore clusters (bold) and the 5 onshore regions. The mean separation is derived using equation 1 based on the wind farms within each region.

\subsection{Spatial separation of capacity}

The addition of offshore wind farms has changed the distribution of capacity in two distinct ways. Firstly, there is an increased concentration of capacity in clusters. For each region the spatial dispersion of the capacity has been quantified in terms of the mean separation per unit MW of capacity, $\mathrm{S}$, as calculated in [12] as:

$$
s=\sum_{i=1}^{N} \frac{c_{i}}{C_{T}}\left(\sum_{j=1}^{N} \frac{c_{j} d_{i j}}{C_{T}}\right)
$$

where $c_{j}$ is the wind farm capacity, $d_{i j}$ is the distance between wind farms, $N$ is the number of wind farms in the region and $C_{T}$ is the total installed capacity of the region. The offshore regions are generally made up of large wind farms clustered together in a relatively small area and consequently have a low separation between units of capacity $(26.9 \mathrm{~km}$ to $38.1 \mathrm{~km})$. In comparison, onshore regions generally consist of spatially dispersed small wind farms therefore the separation of the capacity is larger $(60.7 \mathrm{~km}$ to $115.2 \mathrm{~km})$, with the exception of Lothian $(17.3 \mathrm{~km})$. Secondly, the addition of the offshore regions has changed the geographical location of the generation. Figure 1 shows that all of the onshore zones are located relatively close to each other in Scotland; therefore the mean separation between the onshore capacity is only $168 \mathrm{~km}$. In contrast, all of the offshore clusters are connected to England, and are more geographically dispersed (mean separation of $327.6 \mathrm{~km}$ between the offshore capacity), therefore by combining the onshore and offshore capacity the mean separation between capacity for the GB wind farm distribution increases to $399 \mathrm{~km}$.

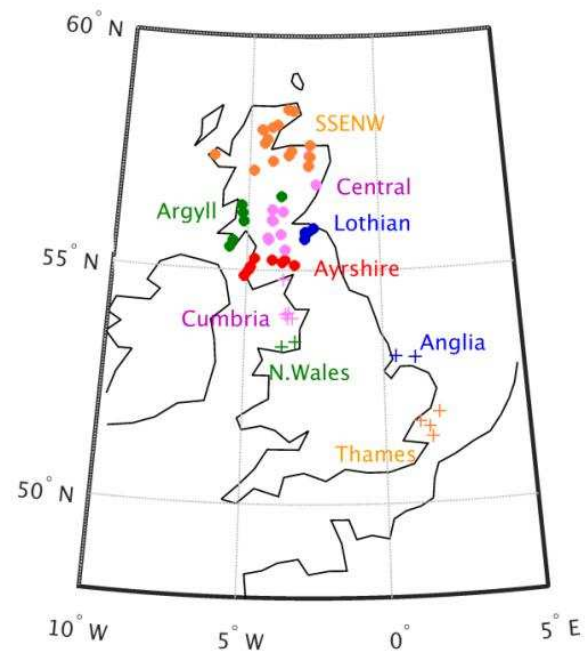

Figure 1 Map of the wind farm distribution used in this study. The onshore and offshore farms are represented by the circles and crosses respectively.

\subsection{Impact of spatial separation on generation characteristics}

To investigate the impact of spatial separation of capacity on wind power variability in Great Britain, the 30-minute averaged time series of aggregated generation for each of the 9 regions have been combined to derive a time series of power output for every possible combination of regions. This ranges from a combination of two regions (36 possibilities) to the single combination of all nine 
regions (GB-aggregate) and therefore amounts to a total of 515 possible wind farm distribution scenarios each with a different number of wind farms and mean separation between capacity. The data are then used to determine the impact of clustering capacity on the high frequency variability of the wind generation.

A range of different metrics have been used to quantify the variability of wind generation. For the purposes of this study a ramp, $\mathrm{R}$, at time, $\mathrm{t}$, is defined as the difference in the power output over a period of time, $\Delta \mathrm{t}$, given by:

$$
R(t)=P(t+\Delta t)-P(t)
$$

where $\mathrm{P}(\mathrm{t})$ is the power output at time, $\mathrm{t}$. Using the 30-minute averaged dataset, a time series of ramps for $\Delta \mathrm{t}=30$ minutes, 60 minutes and 4 hours, has been calculated for each wind farm distribution scenario. The standard deviation, $\sigma$, of each time series is then calculated to quantify the distribution of the ramps for each scenario.

\subsection{Thames Estuary analysis}

Section 3.3 investigates the most extreme ramping events over three time scales (30 minutes, 60 minutes and 4 hours) of a single offshore cluster in order to determine the meteorological mechanisms. The analysis focuses on the offshore wind farms in the Thames Estuary, located approximately 100-200 km east of London, UK. This is the largest of the offshore clusters consisting of 5 individual farms with a total capacity of $1.7 \mathrm{GW}$. Drew et al. [3] presents a detailed analysis of a high frequency ramping event of this cluster which had significant implications on the management of the power system. This study investigates the full range of extreme ramps to determine the meteorological cause.

To determine extreme ramping events the 30 minute averaged time series of the capacity factor of the Thames region (as outlined in section 2.2) has been used. The extreme ramping events for each time window have been defined following a similar method to that outlined in Cutler et al. [6].

- 4 hour ramps: Find all instances where the 30 minute averaged capacity factor changes by more than $40 \%$ within a 4 hour window. Two individual ramps occurring within a 6 hour window of each other are considered the same event.

- 60 minute ramps: After removing the periods of time during which a 4 hour ramp occurs, find the occasions where the 30 minute averaged capacity factor changes by more than $25 \%$ in a 60 minute time window. Two ramps are considered the same event if they occur within 1 hour of each other.

- 30 minute ramps: After removing the periods where either a 4 hour or 60 minute ramp occurs, find the occasions where the 30 minute averaged capacity factor changes by more than $15 \%$ in a 30 minute time window.

To determine the meteorological mechanisms behind extreme ramping events, a number of datasets have been used (Table 2). Firstly, the meteorological conditions in the Thames Estuary region have been determined using 1-minute averaged observations of temperature, wind speed and surface pressure from two nearby Met Office weather stations (shown in Figure 2) and rainfall rate data derived from radar observations for an area of $4884 \mathrm{~m}^{2}$ covering all of the wind farms on a $1 \mathrm{~km}^{2}$ spatial resolution and a 5 minute temporal resolution [26, 27]. On the larger scale, the synoptic scale conditions have been determined using hourly wind fields and surface pressure from Modern-Era Retrospective Analysis for Research and Applications (MERRA) data [28]. 
In addition to determining the meteorological conditions associated with ramps, hourly surface wind field data from MERRA has been used to estimate the aggregated power generation of the wind farms in the region, following the method of Cannon et al. [7]. Firstly, the horizontally gridded surface hourly winds were bi-linearly interpolated to the location of each wind farm. The derived winds were then vertically interpolated to the hub height of the turbines. Finally, the hub-height wind speeds were converted to power output using a transfer function derived from empirical comparisons between the derived wind speeds and recorded wind farm output. The power output was summed over all wind farms to produce an hourly time series of generation of the Thames Estuary cluster.

\begin{tabular}{|l|l|l|l|}
\hline Dataset & Variables & $\begin{array}{l}\text { Temporal } \\
\text { resolution }\end{array}$ & Location \\
\hline $\begin{array}{l}\text { UK Met Office weather } \\
\text { station observations }\end{array}$ & $\begin{array}{l}\text { Air temperature }(\mathrm{C}) \text { at } 1.25 \mathrm{~m} \\
\text { above the ground. } \\
\text { Mean wind speed and maximum } \\
\text { gust at } 10 \mathrm{~m} \text { above the ground } \\
\left(\mathrm{ms}^{-1}\right) . \text { Atmospheric pressure } \\
(\mathrm{hPa}) .\end{array}$ & $\begin{array}{l}\text { 1-minute } \\
\text { Manston }\left(51.346^{\circ} \mathrm{N},\right.\end{array}$ & $\begin{array}{l}\text { Shoeburyness } \\
\left(51.536^{\circ} \mathrm{N}, 0.809^{\circ} \mathrm{E}\right) .\end{array}$ \\
\hline $\begin{array}{l}\text { Met Office rainfall } \\
\text { radar }\end{array}$ & Rainfall rate $\left(\mathrm{mm} \mathrm{hr}^{-1}\right)$ & 5-minute & $\begin{array}{l}\text { Thames Estuary region } \\
\text { (see Figure 2) on } 1 \mathrm{~km}^{2} \\
\text { resolution. }\end{array}$ \\
\hline $\begin{array}{l}\text { MERRA: Modern-Era } \\
\text { Retrospective Analysis } \\
\text { for Research and } \\
\text { Applications }\end{array}$ & $\begin{array}{l}\text { Mean wind speed }\left(\mathrm{ms}^{-1}\right) \text { at } \\
\text { heights of } 2 \mathrm{~m}, 10 \mathrm{~m} \text { and } 50 \mathrm{~m} .^{\text {Surface pressure }(\mathrm{hPa}) .}\end{array}$ & Hourly & $0.667^{\circ}$ global grid. \\
\hline
\end{tabular}

Table 1 Details of the meteorological datasets used in this study.

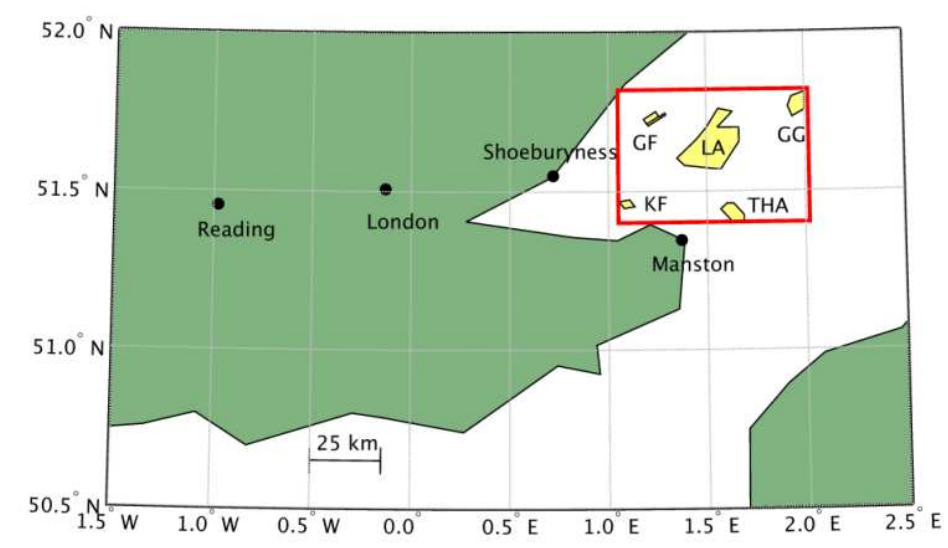

Figure 2 Map showing the location of the 5 wind farms in the Thames Estuary: Greater Gabbard (GG), London Array (LA), Gunfleet Sands (GF), Kentish Flats (KF) and Thanet (THA). The red box indicates the region for which radar rainfall data was obtained. The map also shows the locations of the surface meteorological stations: Manston and Shoeburyness.

\subsection{Results}

The dataset outlined in Section 2 has been used to address a series of questions related to wind power variability. Section 3.1 investigates the impact of the offshore wind farms on the GB-aggregated wind generation characteristics, with a particular emphasis on the impact of changing the separation between capacity and the number of wind farms on the magnitude on the high frequency ramps. Section 3.2 determines the magnitude of regional high frequency power swings for the offshore 
clusters and compares the results to that of the more spatially-dispersed onshore regions. Finally, Section 3.3 quantifies the high frequency ramping of wind farms in the Thames Estuary, the largest offshore cluster and identifies the meteorological mechanism.

\subsection{Impact of clustering capacity on generation variability}

206

This section determines how the magnitude of the ramps in regional wind power varies with two metrics used to define the level of clustering (1) the number of wind farms aggregated and (2) the mean separation between capacity. For all 515 possible wind farm distributions, the time series of power ramps over three time periods ( 30 minutes, 60 minutes and 4 hours) have been determine. The standard deviation of the resulting time series was calculated and is used as a measure of the magnitude of the ramps.
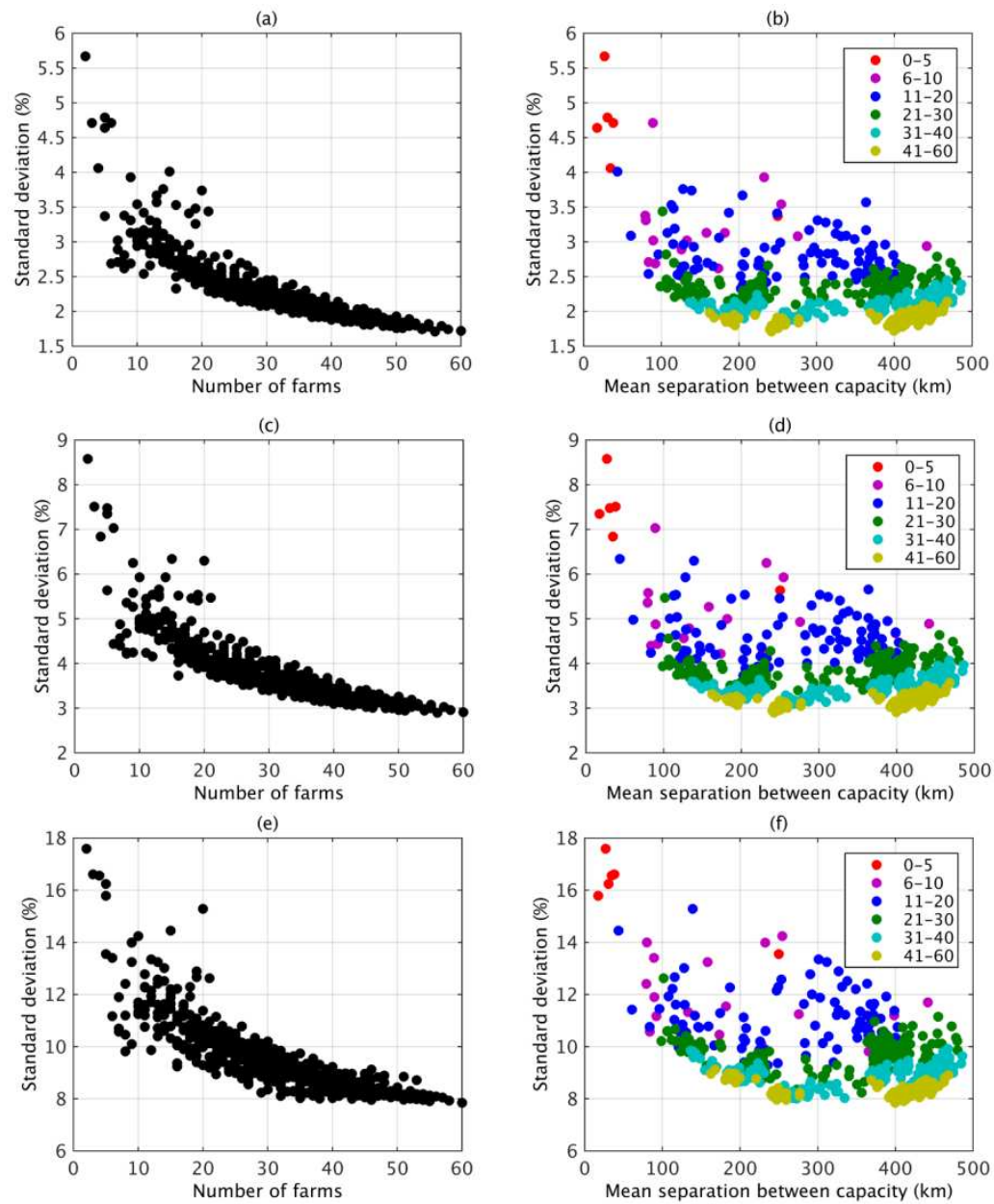

Figure 3 Standard deviation of the power ramps of each of the 515 different wind farm distributions as a function of the number of farms in the distribution and the mean separation between the capacity for three time windows (a)-(b) 30 minutes, (c)-(d) 60 minutes and (e)-(f) 4 hours.

216 For all three time scales, the magnitude of the ramps decreases as the number of wind farms in the distribution increases (see Figures 3(a)-(f)). A large reduction in the standard deviation is shown between 5 and 30 wind farms before levelling off as the number of farms increases further. For example, for the 30 minute ramps the standard deviation decreases from approximately $4.8 \%$ to $2.1 \%$ as the number of wind farms increases from 5 to 25 , but decreases to only $1.9 \%$ as the number of wind farms increases further to 50. However, for all time scales the lowest standard deviation is shown for the largest number of wind farms (i.e. the full GB wind farm distribution). 
This analysis indicates that the number of wind farms aggregated is a useful parameter for estimating the distribution of power swings on time scales of 30 minutes to 4 hours. In comparison, the separation between capacity is not a good indicator of the size of the ramps. For all time scales, increasing the separation (but keeping the number of wind farms the same) has little impact on the size of the ramps (see Figures 3(b), 3(d) and 3(f). For example, for a wind farm distribution which contains 41-60 farms, if the separation between the units of capacity is $200 \mathrm{~km}$ the standard deviation of the 30 minute ramps is between $1.8 \%$ and $2.0 \%$. If the separation were to increase to $400 \mathrm{~km}$ the standard deviation is very similar $(1.7 \%-2.0 \%)$. These results suggest that on the time scales considered, the power ramps of the regions are not well correlated, therefore the magnitude of the aggregated ramps decrease as more and more regions (number of farms) are added, irrespective of any potential change in the separation between capacity.

\subsection{Regional power ramps}

The analysis in section 3.2 has shown that the magnitude of the power ramps of a wind farm distribution is highly dependent on the number of wind farms. The recent trend of concentrating a small number of very large wind farms therefore results in an increase in the magnitude of the local power ramps. Figures 4 to 6 show the distribution of the power ramps for each region in Great Britain in 2014. For all time intervals, the distribution is approximately symmetric with median values close to zero for both the onshore and offshore regions, indicating that positive and negative ramps have a similar distribution.

In general, when considered in terms of a change in capacity factor, the magnitude of the ramps is larger for the offshore clusters for all time scales. Consequently, if the system operator were to hold reserve to protect against a 90th percentile swing, for the onshore regions it would equate to on average $3.8 \%, 6.0 \%$ and $14.5 \%$ of capacity for 30 minutes, 60 minutes and 4 hours respectively. In comparison a similar holding for the offshore regions would equate to an average of $4.8 \%, 7.9 \%$ and $18.9 \%$ of capacity. This is due to the offshore clusters containing a lower number of farms than the onshore zones. As the 4 offshore regions have a similar number of farms, the magnitude of ramps is very similar for all offshore regions- with slight differences in the extreme values. For the onshore regions, there is generally a larger spread in the distributions reflecting the variability in the number of farms across the regions. For example, for Lothian there are a similar number of wind farms to the offshore regions and the standard deviation of the ramps is $4.7 \%, 7.6 \%$ and $17.9 \%$ for 30 minutes, 60 minutes and 4 hours respectively.

When considered in terms of change in power (MW), due to large capacity in Thames Estuary, the ramps of the cluster are larger than all other regions for all time scales (as shown in Figures 4-6 (c)). For example, for the 30 minutes, 60 minutes and 4 hour time window, the maximum ramp in the Thames Estuary is $777 \mathrm{MW}, 886 \mathrm{MW}$ and $1363 \mathrm{MW}$. Power ramps of this magnitude could potentially pose a challenge to those responsible for maintaining a balance between supply and demand on the power system. Accurate meteorological forecasting is critical to decisions made on holding reserve, but can be difficult on such short timescales. Here follows a detailed investigation into the meteorological conditions causing ramps in the Thames Estuary, to inform development of accurate forecasts. 

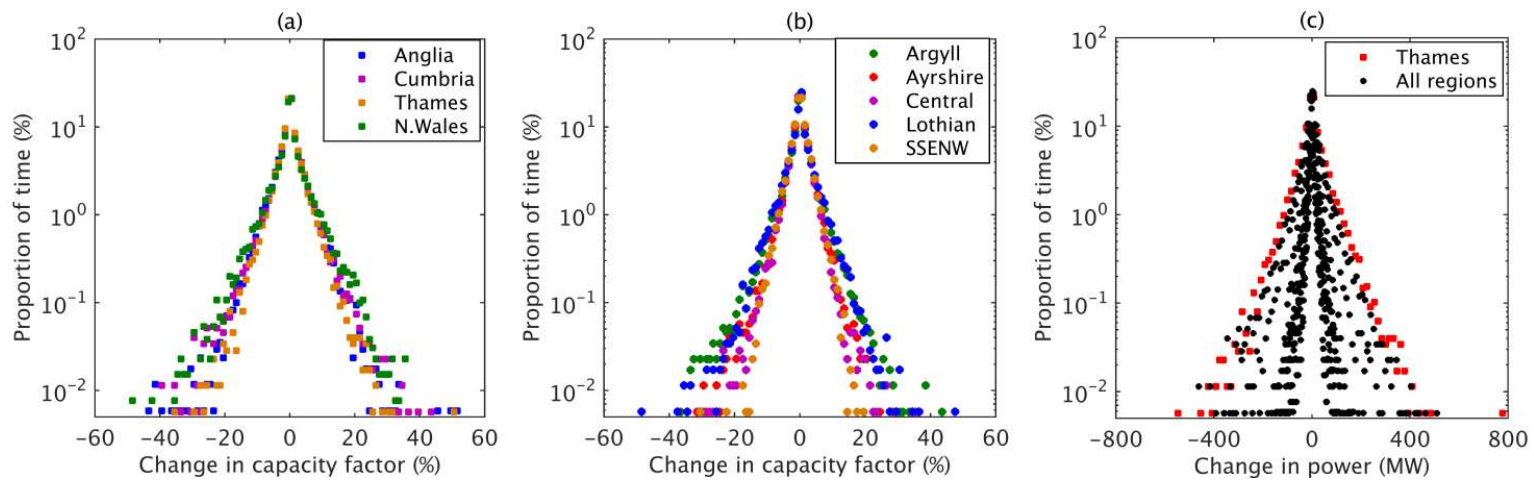

Figure 4 Distribution of the change in capacity factor within a 30 minute time window in 2014 for (a) offshore clusters (b) onshore regions. (c) The ramps expressed in terms of power (MW).
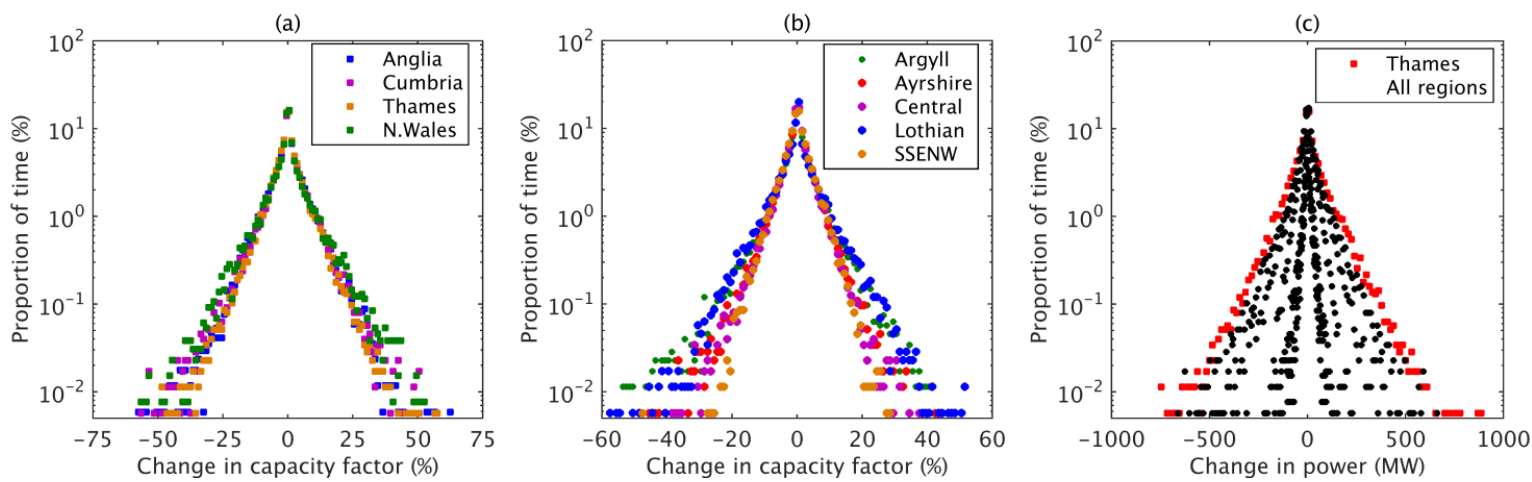

Figure 5 Distribution of the change in capacity factor within a 60 minute time window in 2014 for (a) offshore clusters (b) onshore regions. (c) The ramps expressed in terms of power (MW).
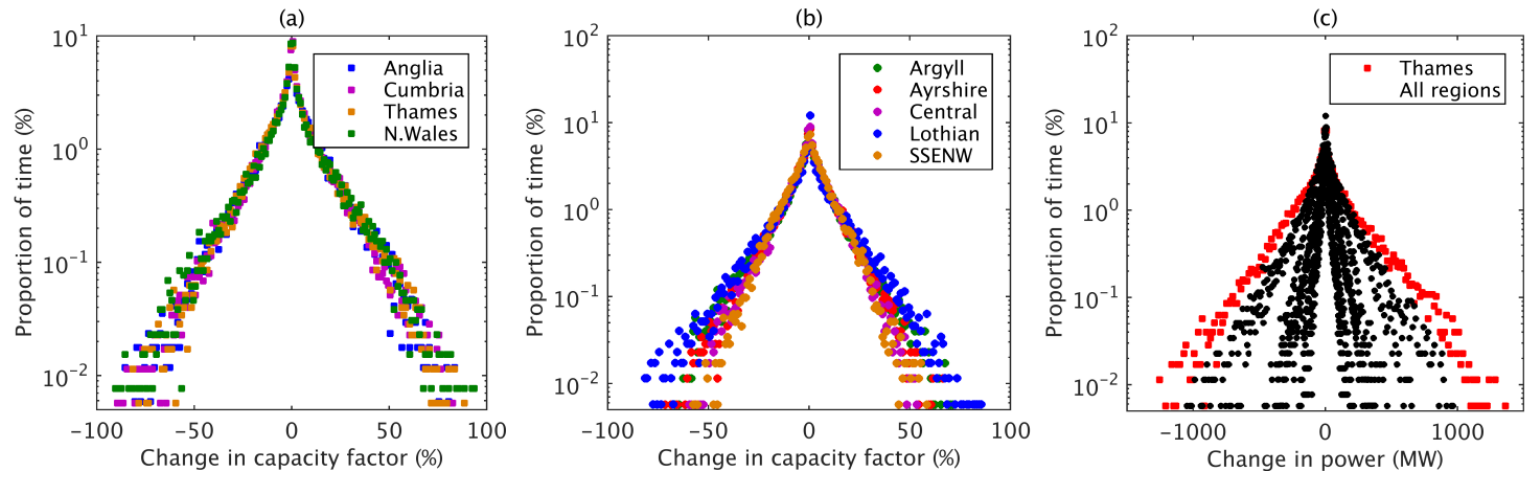

270 Figure 6 Distribution of the change in capacity factor within a 4 hour time window in 2014 for (a) offshore clusters (b) onshore regions. (c) The ramps expressed in terms of power (MW).

\subsection{Thames Estuary ramping}

In Section 3.2 it was shown that the clusters of offshore wind farms can lead to large high frequency regional power ramps. This section analyses the generation data from the Thames Estuary cluster (the largest of the offshore clusters in terms of capacity) in more detail, to identify the extreme ramping events and determine the meteorological drivers. As with the previous sections, the analysis has been completed on three time scales (30 minutes, 60 minutes and 4 hours).

\section{3.3.1 Extreme ramps over a 4-hour time window}

279 Following the method outlined in section 2.3 (the hourly capacity factor changes by more than $40 \%$ over a 4 hour time window), 74 ramp-up events and 69 ramp-down events were identified. Events occurred throughout the year, however a larger proportion occurred in winter (39\% in DJF) than any 
of the other seasons (22\% in MAM, 24\% in JJA and 15\% in SON). The most extreme ramp-up event was $86.2 \%$ which equates to a change in power of $1.3 \mathrm{GW}$ and the most extreme ramp-down was $76.7 \%$ which equates to a change in power of $1.2 \mathrm{GW}$.

For each event, the synoptic meteorological conditions have been investigated using the surface pressure data from MERRA (see figure 7). All of the extreme ramping events on this time scale can be linked to the passage of an extra-tropical cyclone (low pressure system) and the associated weather fronts. For all of the 74 ramp-up events, there is a clear pattern in the surface pressure field. A low pressure system is centred over Iceland and the frontal features stretch south-east across the UK. There is a similar pattern for the ramp-down events however the centre of the low pressure has moved eastwards and the gradient in surface pressure over the UK has weakened. Additionally, the frontal features are now located east of the cluster.

By applying the method developed in Cannon et al. [7], the hourly generation of the Thames Estuary cluster in 2014 has been estimated based on the surface wind field given by MERRA. The derived data have been analysed to determine whether extreme ramping events are captured. MERRA is defined to have captured a ramp if it is at least $75 \%$ of the size of the measured ramp within a \pm 3 hour time window of when it occurred. Based on this criterion, the MERRA derived data captures all 74 ramp-up events and 69 ramp-down events which occurred in the Thames Estuary offshore cluster during 2014. This confirms that the extreme ramping on this time scale is the result of synoptic scale meteorological features which are well reproduced by the reanalysis product.

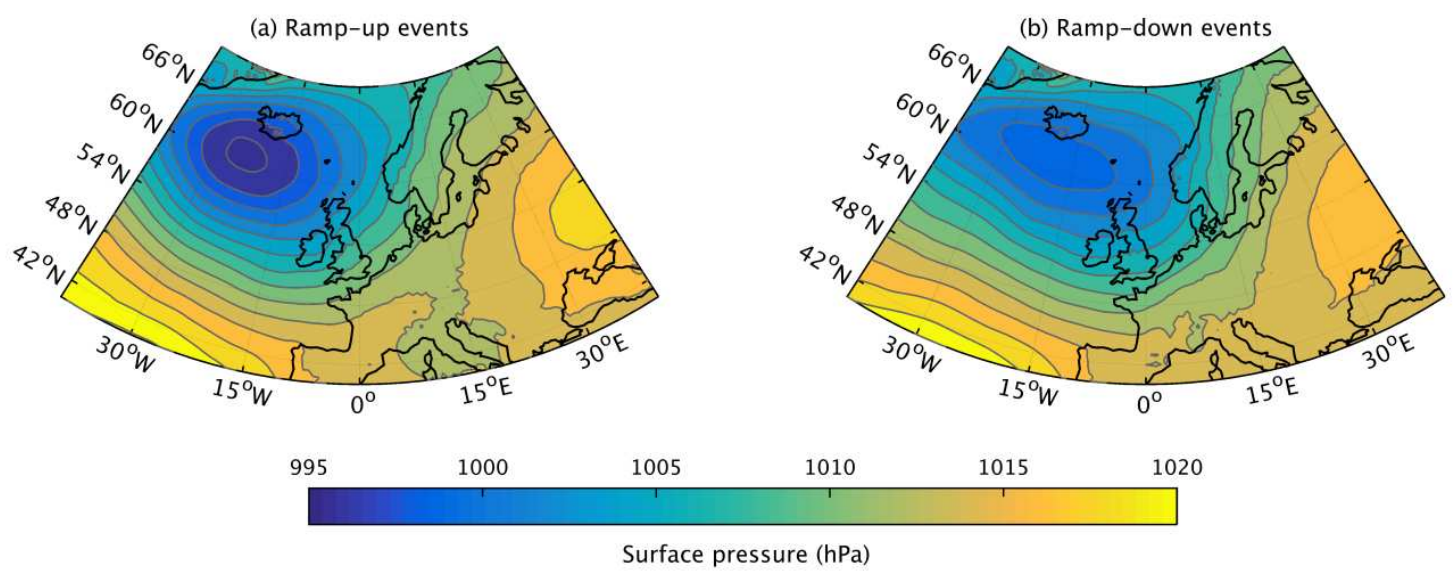

Figure 7 Mean sea level pressure averaged across all (a) 74 ramp-up events and (b) 69 ramp-down events.

\subsubsection{Extreme ramps over a 1-hour time window}

For the full year of measured data, power ramps over a one hour time window have been calculated and the frequency distribution of the ramps is shown in Figure 8 (this is the same data as the Thames curve in Figure 5(a)). The data have then been filtered to remove the periods which contain a 4 hour ramp (identified in section 3.3.1) and the distribution of the filtered ramps is also shown in Figure 8. A comparison of the probability density functions shows the most extreme 60 minute ramping events are the same in both distributions. For the both the filtered and unfiltered datasets the largest rampdown is $-48.8 \%$ and the largest ramp-up event is $57.9 \%$. This indicates that the most extreme 1 hour ramps are not part of a larger scale ramp and are therefore not caused by the passage of low pressure system but by smaller scale meteorological features. 


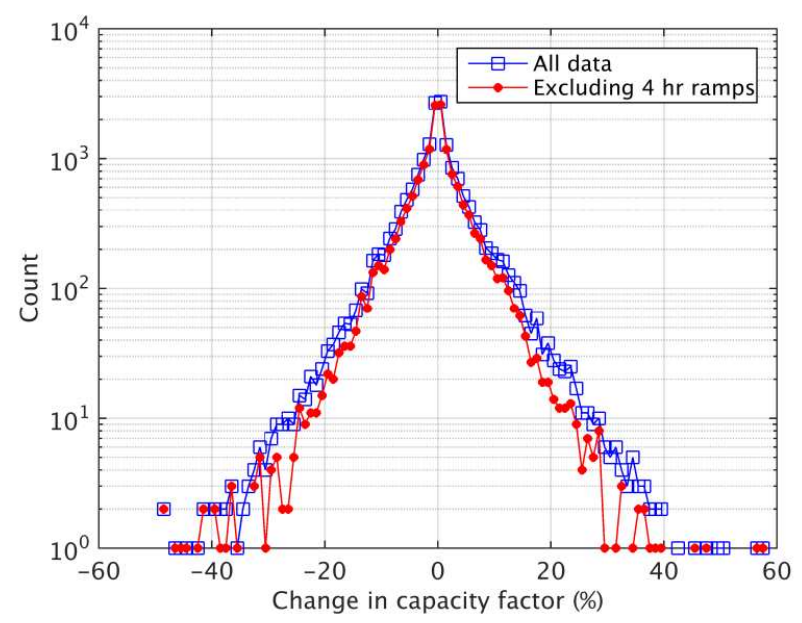

Figure 8 The 60 minute ramps for the Thames Estuary cluster during 2014 using the whole dataset (blue) and then excluding the periods during which a 4 hour ramp occurs.

Using the criteria outlined in section 2.3, 24 x 1 hour extreme ramping events have been identified.

317 Further analysis shows, on 10 occasions an extreme ramp-up and ramp-down occurred within 3 hours

318 of each other (as shown in Table 3). These ramps were combined to produce 14 independent events. For each event, the meteorological conditions have been investigated using surface pressure fields from MERRA, observations of surface temperature and wind speed from Met Office weather stations close to the cluster (Manston and Shoeburyness) and rainfall radar data. Based on the meteorological data, 3 main drivers of the extreme ramping on this time scale have been identified; (1) turbine cut-out due to high wind speed conditions (2) outflow or gust fronts from thunderstorms and (3) organised band of convection following a frontal system.

\subsubsection{High wind speed cut-out}

There were 5 ramping events associated with the high wind speed shutdown of turbines. The largest of which occurred on $14^{\text {th }}$ February 2014, when the output of the farms reduced by $44.3 \%$ (i.e. a reduction in power output of $680 \mathrm{MW}$ in 1 hour). All 5 of the cut-out ramping events occurred in winter and are associated with a low pressure system located over the UK. The strong pressure gradient leads to very high wind speeds in the Thames Estuary region. For all of the events, the 1 minute mean wind speed at both Manston and Shoeburyness exceeds $25 \mathrm{~ms}^{-1}$ during the period when generation is reduced.

Three of the five events are characterised by a large reduction in the output as the turbines cut-out followed by a similar sized ramp-up. For example, on $25^{\text {th }}$ January 2014 at 16:00 there was a reduction in capacity factor of the cluster by $28.6 \%$ (see Figure 9) which corresponds to a spike in wind speeds observed in the region (at Manston, the mean wind speed peaked at $35.5 \mathrm{~ms}^{-1}$ at 17:30). Following this, there is a reduction in wind speeds and therefore the turbines start to generate again and therefore there is a ramp-up of $26.7 \%$ at 17:00. 


\begin{tabular}{|c|c|c|c|c|c|}
\hline No. & Date & $\begin{array}{c}\text { Ramp-up (\%) } \\
\text { and time }\end{array}$ & $\begin{array}{c}\text { Ramp-down (\%) } \\
\text { and time }\end{array}$ & $\begin{array}{c}\text { Maximum } \\
\text { rainfall rate } \\
\left(\mathrm{mm} \mathrm{hr}^{-1}\right)\end{array}$ & Type \\
\hline 1 & $25 / 01$ & $26.7(17: 00)$ & $-28.6(16: 00)$ & 91 & Cut-out \\
\hline 2 & $12 / 02$ & $38.3(16: 30)$ & $-29.0(14: 00)$ & 15 & Cut-out \\
\hline 3 & $14 / 02$ & & $-44.3(22: 00)$ & 26 & Cut-out \\
\hline 4 & $07 / 03$ & $27.6(20: 00)$ & & 150 & Post-frontal \\
\hline 5 & $23 / 03$ & $32.6(16: 30)$ & $-28.4(17: 30)$ & 71 & Thunderstorms \\
\hline 6 & $24 / 05$ & $26.3(16: 30)$ & & 97 & Post-frontal \\
\hline 7 & $07 / 06$ & $45.4(08: 30)$ & $-48.8(10: 00)$ & 12 & Thunderstorms \\
\hline 8 & $18 / 07$ & $57.9(19: 30)$ & $-42.5(22: 00)$ & 1023 & Thunderstorms \\
\hline 9 & $19 / 07$ & $39.1(04: 30)$ & $-25.4(07: 00)$ & 64 & Thunderstorms \\
\hline 10 & $19 / 07$ & $28.6(19: 30)$ & $-28.4(20: 30)$ & 115 & Thunderstorms \\
\hline 11 & $14 / 08$ & $26.8(14: 30)$ & $-45.9(15: 30)$ & 396 & Thunderstorms \\
\hline 12 & $03 / 11$ & $31.1(13: 30)$ & $-48.8(15: 30)$ & 147 & Post-frontal \\
\hline 13 & $19 / 12$ & $36.9(09: 30)$ & $-39.8(07: 00)$ & 622 & Cut-out \\
\hline 14 & $26 / 12$ & & $-36.3(23: 30)$ & 77 & Cut-out \\
\hline
\end{tabular}

Table 3 Meteorological conditions for the 60 minute ramping events which occurred in the Thames Estuary in 2014 identified using the method outlined in section 2.3 .
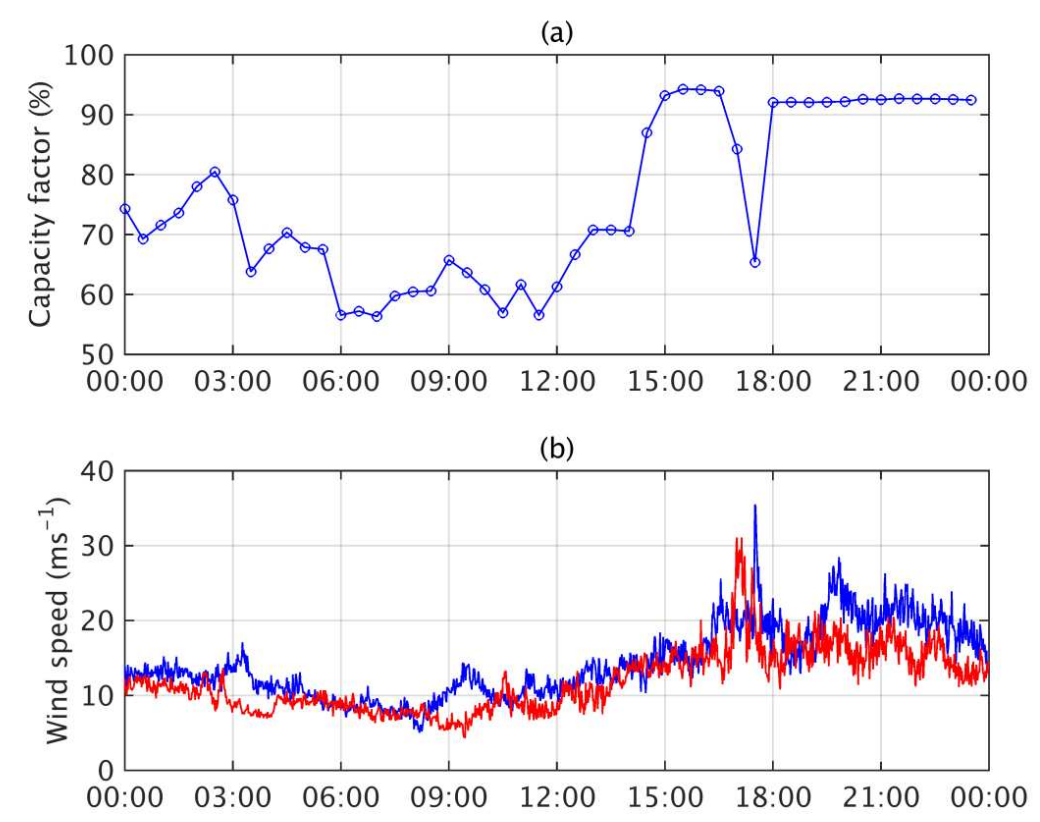

350 Figure 9 Meteorological conditions on 25th January 2014. (a) 30 minute averaged wind power generation of the 351 Thames Estuary cluster (expressed in terms of capacity factor) (b) 1-minute averaged wind speed observations from 352 Manston (blue) and Shoeburyness (red). 
(a)
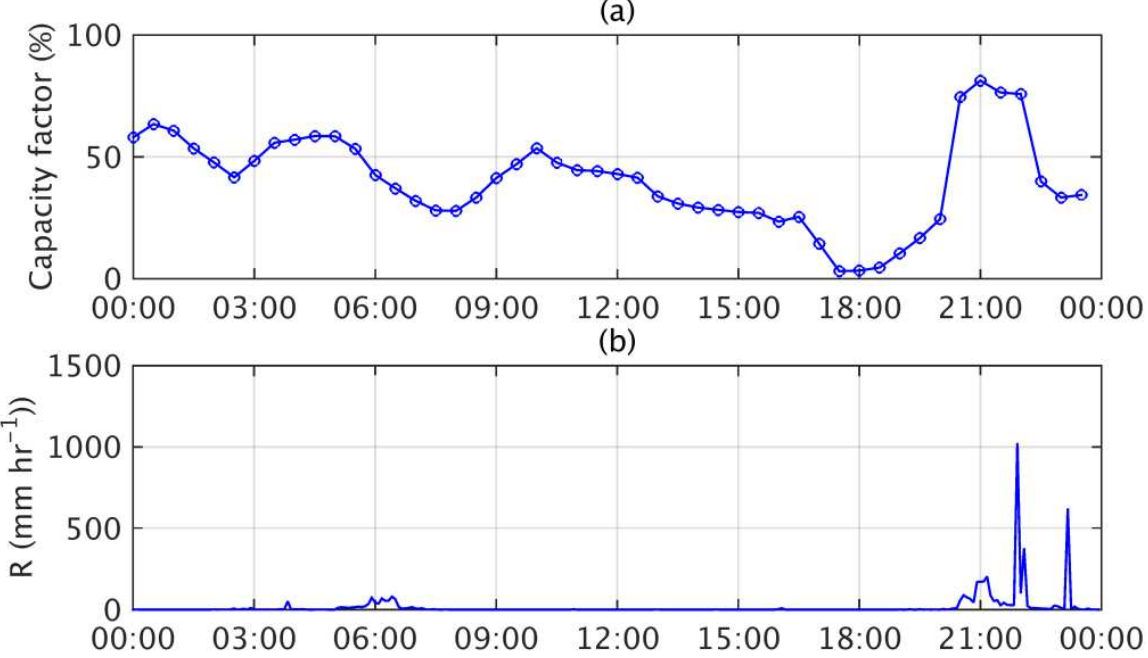

(c)

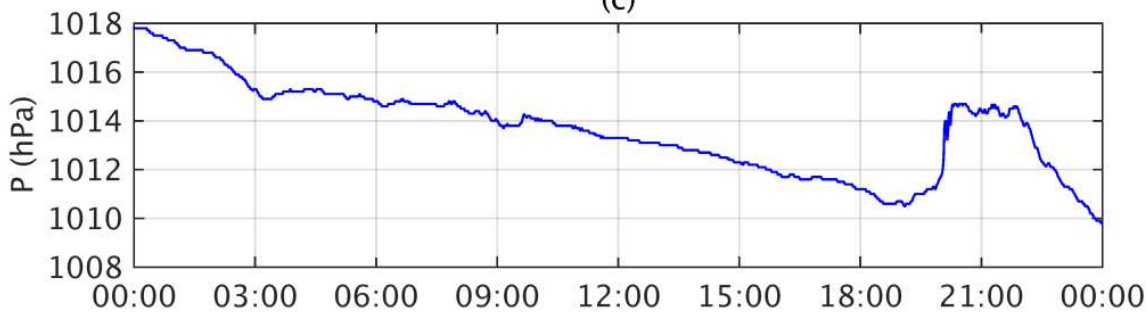

Figure 10 Meteorological conditions for the wind power ramping event on $18^{\text {th }}$ July 2014 . (a) 30 minute averaged wind power generation of the Thames Estuary cluster (expressed in terms of capacity factor) (b) the maximum rainfall rate of any gridbox in the Thames Estuary on a 5 minute resolution and (c) 1-minute surface pressure observations from Manston.

\subsubsection{Thunderstorms}

There were 6 ramping events caused by the wind speed gusts associated with a thunderstorm ( 2 on $19^{\text {th }}$ July 2014), all of which occurred between March and August. For these events the atmospheric conditions are dominated by a high pressure system (anticyclonic) located over the UK and a low pressure system to the south west. Analysis of the meteorological conditions in the Thames Estuary shows that all ramps coincide with other meteorological conditions which are a signature of the thunderstorm, such as a period of heavy rainfall in the region and large fluctuations in temperature. For example, the maximum rainfall rate during the ramp for any $1 \mathrm{~km}$ radar gridbox in the Thames Estuary exceeds $64 \mathrm{~mm} \mathrm{hr}^{-1}$ - for all but one of the ramping events. Furthermore, observations at Manston and Shoeburyness show there is generally sharp drop in temperature during the ramping event.

The largest ramping event associated with a thunderstorm occurred on the $18^{\text {th }}$ July 2014 . At 19:30 the capacity factor of the cluster increased by $57.9 \%$ ( $890 \mathrm{MW}$ in $1 \mathrm{hr}$ ). Figure 10 shows this ramp coincided with very heavy rainfall across the region. The maximum rainfall rate derived from the radar observations was $1023 \mathrm{~mm} \mathrm{hr}^{-1}$ at 22:00. In addition, the surface pressure observed at Manston increased by $4 \mathrm{hPa}$ in a 25 minute period (Figure 10(c)).

Three events are caused by a band of increased wind speeds which occur after a front. The elevated wind speeds lead to an increase in power output from the cluster for a short period of time before the 
feature moves away from the region. As with the thunderstorms, there is also a signature of these features in the rainfall data. Figure 11 shows the capacity factor of the Thames Estuary wind farms on $24^{\text {th }}$ May 2014 and the mean rainfall rate across the region. During the morning a weather front moved across the South East of England which led to high wind speeds and heavy rainfall. After the front moved eastwards away from the cluster of farms, their wind generation reduced dramatically, falling from $69.7 \%$ of capacity at $08: 00$ to only $23.7 \%$ at $13: 00$. In the mid-afternoon there was an increase in wind power generation and by 17:00 the output was back up to $62.6 \%$, however this ramp had a short duration and by 20:00 the output had reduced to only $30.0 \%$. Figure 11(b) shows a corresponding ramp in the rainfall in the region.
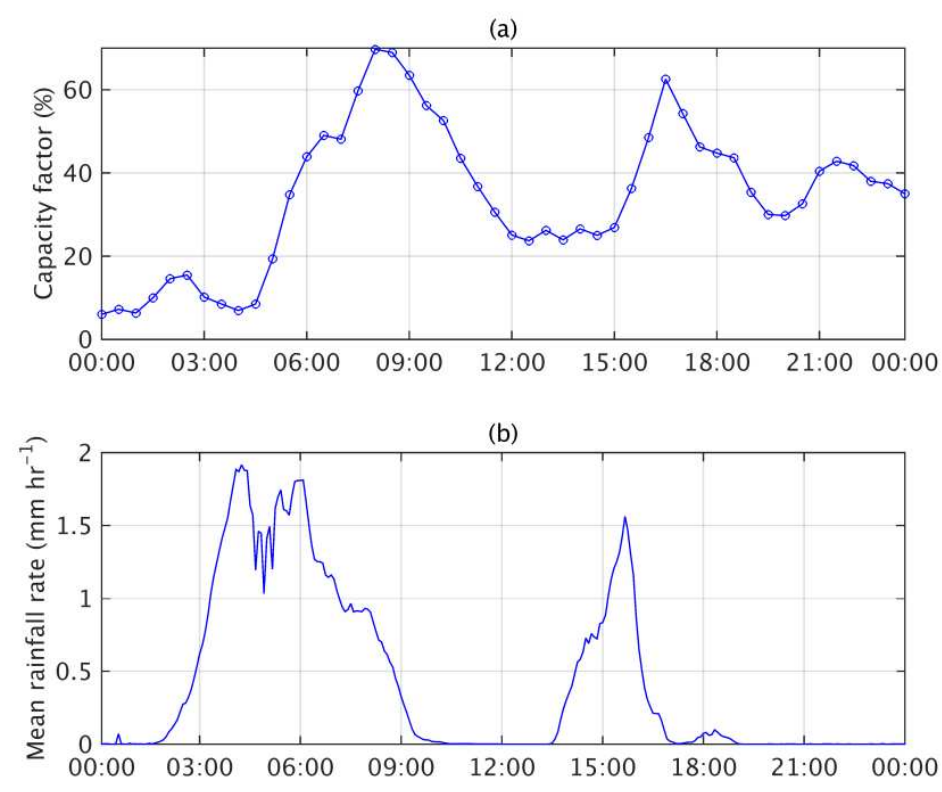

Figure 11 Meteorological conditions for the wind power ramping event and the meteorological conditions on $24^{\text {th }}$ May 2014. (a) The 30 minute averaged wind power generation of the Thames Estuary cluster (expressed in terms of capacity factor) and (b) the mean rainfall rate across the Thames Estuary on a 5 minute resolution.

For the full year of the data the power ramps over a 30 minute time window have been calculated using the method outlined in Section 2.3. The data have then been filtered to remove the periods which correspond to a 4 hour ramp (derived in section 3.3.1). As with the 60 minute ramps, Figure 12 shows that the most extreme 30 minute ramping events are not associated with a larger scale ramp and therefore are not caused by the passage of low pressure system but by a smaller scale meteorological feature.

Using the method outlined in section 2.3, only 630 -minute ramping events have been identified (see Table 4). For each event, the meteorological mechanism has been determined using a range of datasets. Based on the analysis, 4 of the ramps were shown to be associated with the high wind speed 


\begin{tabular}{|c|c|c|c|c|c|}
\hline No. & Date & $\begin{array}{c}\text { Ramp-up (\%) } \\
\text { and time }\end{array}$ & $\begin{array}{c}\text { Ramp-down (\%) } \\
\text { and time }\end{array}$ & $\begin{array}{c}\text { Maximum } \\
\text { rainfall rate } \\
\left(\mathrm{mm} \mathrm{hr}^{-1}\right)\end{array}$ & Type \\
\hline 1 & $03 / 01$ & & $-18.3(15: 30)$ & 9 & Cut-out \\
\hline 2 & $26 / 01$ & & $-16.0(18: 00)$ & 8 & Cut-out \\
\hline 3 & $28 / 01$ & & $-17.4(04: 00)$ & 37 & Cut-out \\
\hline 4 & $01 / 02$ & $15.2(07: 30)$ & & 14 & Cut-in \\
\hline 5 & $19 / 07$ & $21.3(08: 30)$ & & 19 & Thunderstorm \\
\hline 6 & $19 / 07$ & $16.7(12: 00)$ & & 20 & Thunderstorm \\
\hline
\end{tabular}

Table 4 Details of the 30 minute ramping events which occurred in the Thames Estuary in 2014 identified using the method outlined in section 2.3.

407

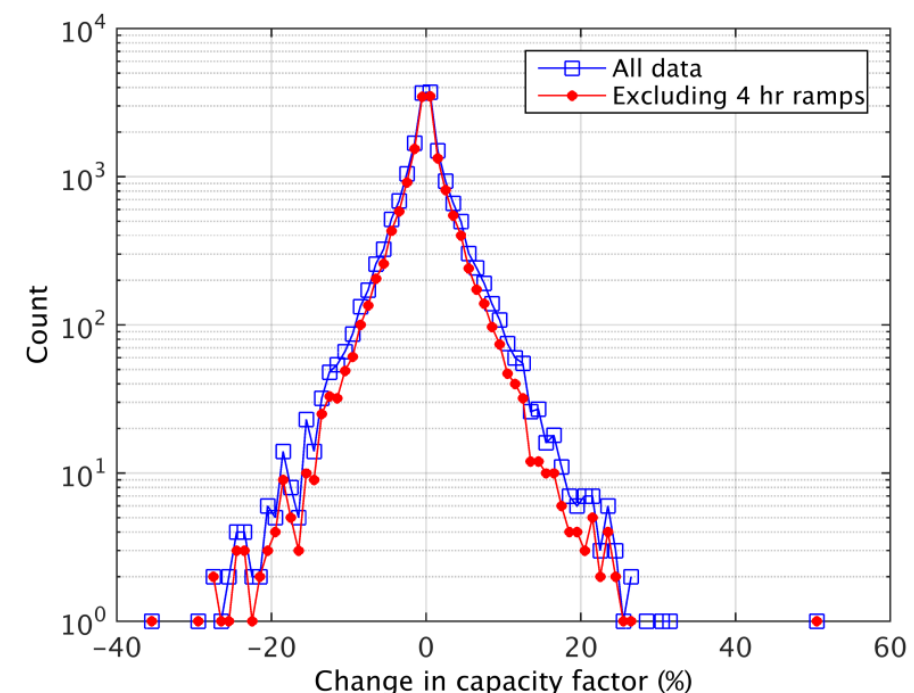

Figure 12 The 30 minute ramps for the Thames Estuary cluster during 2014 using the whole dataset (blue) and then excluding the periods during which a 4 hour ramp occurs.

\subsection{Conclusions}

In recent years there has been a significant change in the distribution of wind capacity in the UK, with the construction of several clusters of very large offshore wind farms. This paper investigates how this change has affected the magnitude of the nationally aggregated and regionalised ramps on temporal scales which are critical for the management of the power system (30 minute, 60 minute and 4 hours). In addition, the extreme high frequency ramps of the largest cluster of offshore wind farms (Thames Estuary) have been investigated in detail to determine the meteorological drivers.

Despite the clustering of capacity in relatively small areas, the addition of the offshore wind farms reduces the high frequency variability of nationally aggregated generation. This study has used two key parameters to quantify the level of clustering; (1) number of wind farms in the region (2) mean separation between capacity. The level of the variability has been considered in terms of the magnitude of the power ramps on the three timescales which are of importance for system management (30 minutes, 60 minutes and 4 hours). For this metric, the magnitude of the variability was highly correlated to the number of wind farms aggregated. As the number of wind farms in the distribution increases, the magnitude of the ramps decreases. This reduction is particularly large between 5 and 25 wind farms before levelling off as the number of farms increases further. In contrast, the mean separation between capacity had little impact on the magnitude of the power swings. In fact, keeping the number of wind farms fixed but changing the separation has a negligible impact on the standard deviation of the distribution of the power swings. These results show that the ramps on these time scales in the different regions are not correlated; therefore aggregating the regions leads to a smoothing effect. 
As the magnitude of the high frequency power swings are highly dependent on the number of wind farms, the recent trend in Great Britain for clustering capacity in a small number of very large wind farms results in an increase in the local power swings. For example, if the system operator were to hold reserve to protect against a $90^{\text {th }}$ percentile swing, for the onshore regions in 2014 it would equate to on average $3.8 \%, 6.0 \%$ and $14.5 \%$ of capacity for 30 minutes, 60 minutes and 4 hours respectively. In comparison, a similar holding for the offshore regions would equate to an average of $4.8 \%, 7.9 \%$ and $18.9 \%$ of capacity. Consequently, for clusters with high levels of capacity this could lead to very large ramps in power. For example, for the Thames Estuary, an $18.9 \%$ ramp equates to a change in power of $290 \mathrm{MW}$. This effect would be exacerbated in the future with the development of even larger clusters (e.g. Dogger Bank which could have a capacity in excess of $4 \mathrm{GW}$ ).

The meteorological conditions leading to extreme high frequency ramping of an offshore cluster have been investigated in more detail using the Thames Estuary as a case study. Over a 4 hour time window, the largest ramp in capacity factor was $86.2 \%$ (which equates to a power swing of $1.3 \mathrm{GW}$ ). This, along with the other extreme 4 hour ramping events was caused by the passage of a cyclone and the associated weather fronts. On shorter time scales, the largest ramping events over 30 minute and 60 minute time windows are not associated with the passage of fronts. They are caused by three main meteorological mechanisms; (1) very high wind speeds associated with a cyclone causing turbine cutout (2) gusts associated with thunderstorms and (3) organised band of convection following a front.

To minimise the balancing costs associated with the extreme high frequency ramping events the meteorological features need to be captured by the wind power forecast. Drew et al. [3] has shown that high resolution ensemble models are able to capture the elevated wind speed associated with postfrontal convection. However, the timing and location of the feature may not be exactly correct. This study has shown that this problem could potentially be addressed by considering the use of real time meteorological observations, such as data from the rainfall radar to adjust the forecast in real-time if necessary.

\section{Acknowledgements}

This work was funded by National Grid via the Network Innovation Allowance (NIA_NGET0128). The authors would particularly like to thank David Lenaghan (National Grid) for helpful advice throughout this project and the aggregated wind farm generation data used in this paper. Thanks also to Dr Rob Thompson from the University of Reading for his assistance with the radar rainfall data.

\section{References}

1. Department for Business, Energy and Industrial Strategy (2017). Energy Trends June 2017. Available from https://www.gov.uk/government/statistics/energy-trends-june-2017

2. Heptonstall, P., Gross, R. and Steiner, F. (2016). The costs and impacts of intermittency- 2016 update. UK Energy Research Centre's Technology and Policy Assessment function.

3. Drew, D.R., Barlow, J. F., Coker, P.J., Frame, T., and Cannon, D.J, (2017) The importance of forecasting regional wind power ramping: A case study for the UK. Renewable Energy, 114, pp 1201-1208.

4. Potter, C. W., Grimit, E., \& Nijssen, B. (2009). Rapid Ramp Event Forecast Tool. IEEE Power systems Conference (pp. 1-5). Seattle, Washington. 
5. Bossavy, A., Girard, R., \& Kariniotakis, G. (2013). Forecasting ramps of wind power production with numerical weather prediction ensembles. Wind Energy, (February 2012), 5163. doi:10.1002/we

6. Cutler, N., Kay, M., Jacka, K., \& Nielsen, T. S. (2007). Detecting, Categorizing and Forecasting Large Ramps in Wind Farm Power Output Using Meteorological Observations and WPPT. Wind Energy, (July), 453-470. doi:10.1002/we

7. Cannon, D. J., Brayshaw, D. J., Methven, J., Coker, P. J., \& Lenaghan, D. (2015). Using reanalysis data to quantify extreme wind power generation statistics: A 33 year case study in Great Britain. Renewable Energy, 75, 767-778. doi:10.1016/j.renene.2014.10.024

8. Department of Energy and Climate Change (2013). UK renewable energy roadmap- update 2013. Retrieved from https://www.gov.uk/government/publications/uk-renewable-energyroadmap-second-update.

9. RenewableUK. UK Wind Energy Database

(UKWED) http://www.renewableuk.com/en/renewable-energy/wind-energy/uk-wind-energydatabase/index.cfm (accessed June 2017).

10. Higgins, P., \& Foley, A. The evolution of offshore wind power in the United Kingdom. (2014) Renewable and Sustainable Energy Reviews 37, 599-612. doi:10.1016/j.rser.2014.05.058.

11. National Grid. UK Future energy scenarios. Retrieved from http://www2.nationalgrid.com/mediacentral/uk-press-releases/2013/national-grid-s-uk-futureenergy-scenarios-2013/ 2013.

12. Drew, D., Cannon, D., Brayshaw, D., Barlow, J., \& Coker, P. (2015). The Impact of Future Offshore Wind Farms on Wind Power Generation in Great Britain. Resources, 4(1), 155-171. doi:10.3390/resources4010155

13. Vincent, C. L., Pinson, P., \& Giebel, G. (2010). Wind fluctuations over the North Sea. International Journal of Climatology, 1595(June 2010), n/a-n/a. doi:10.1002/joc.2175]

14. Trombe, P., Pinson, P., Vincent, C., Bøvith, T., Cutululis, N. A., Draxl, C., Giebel, G., et al. (2013). Weather radars - the new eyes for offshore wind farms? Wind Energy, vol 17, no. 11, pp. 1767-1787, doi:10.1002/we

15. Kubik, M. L., Brayshaw, D. J., Coker, P. J., \& Barlow, J. F. (2013). Exploring the role of reanalysis data in simulating regional wind generation variability over Northern Ireland. Renewable Energy, 57, 558-561. doi:10.1016/j.renene.2013.02.012

16. Hurley and Watson (2002). An assessment of the expected variability and load following of a large wind penetration in Ireland. In proceedings of Global Wind Power Conference. Paris, France.

17. Hasche, B. (2010). General statistics of geographically dispersed wind power. Wind Energy, (April), 773-784. doi:10.1002/we330-342. 
18. Giebel, G. (2001). On the benefits of distributed generation of wind energy in Europe. University of Oldenburg.

19. Landberg, L. (2007). The availability and variability of the european wind resource. International Journal of Solar Energy, 18(4), 313-320. doi:10.1080/01425919708914326

20. Buttler, A., Dinkel, F., Franz, S., \& Spliethoff, H. (2016). Variability of wind and solar power - An assessment of the current situation in the European Union based on the year 2014. Energy, 106, 147-161. doi:10.1016/j.energy.2016.03.041

21. Huber, M., Dimkova, D., \& Hamacher, T. (2014). Integration of wind and solar power in Europe: Assessment of flexibility requirements. Energy, 69, 236-246. doi:10.1016/j.energy.2014.02.109

22. Sinden, G. (2007). Characteristics of the UK wind resource: Long-term patterns and relationship to electricity demand. Energy Policy, 35(1), 112-127. doi:10.1016/j.enpol.2005.10.003

23. Earl, N., Dorling, S., Hewston, R., \& Von Glasow, R. (2013). 1980-2010 Variability in U.K. Surface Wind Climate. Journal of Climate, 26(4), 1172-1191. doi:10.1175/JCLI-D-1200026.1

24. Cradden, L., Restuccia, F., Hawkins, S., \& Harrison, G. (2014). Consideration of wind speed variability in creating regional aggregate wind power time series. Resources, 3(1), 215-234. doi:10.3390/resources3010215

25. Department of Energy and Climate Change. Digest of United Kingdom Energy Statistics 2015; https://www.gov.uk/government/collections/digest-of-uk-energy-statistics-dukes, 2015

26. Met Office (2003): Met Office Rain Radar Data from the NIMROD System. NCAS British Atmospheric Data Centre, http://catalogue.ceda.ac.uk/uuid/82adec1f896af6169112d09cc1174499

27. UK Meteorological Office. Met Office integrated data archive system (MIDAS) land surface station data (1853-current) NCAS British Atmospheric Data Centre. Available from http://badc.nerc.ac.uk/

28. Rienecker, M. M., Suarez, M. J., Gelaro, R., Todling, R., Bacmeister, J., Liu, E., Bosilovich, M. G., et al. (2011). MERRA: NASA's Modern-Era Retrospective Analysis for Research and Applications. Journal of Climate, 24(14), 3624-3648. doi:10.1175/JCLI-D-11-00015.1. 


\title{
1 Identifying and characterising large ramps in power output of 2 offshore wind farms
}

3 Daniel. R. Drew ${ }^{1} *$, Janet. F. Barlow ${ }^{1}$ and Phil. J. Coker ${ }^{2}$

$4 \quad 1$ Department of Meteorology, University of Reading, Reading, UK

52 School of Construction Management and Engineering, University of Reading, Reading, UK

6 * Author to whom correspondence should be addressed; E-Mail: d.r.drew@reading.ac.uk;

$7 \quad$ Tel.: $+44(0) 1183787696$

\begin{abstract}
Recently there has been a significant change in the distribution of wind farms in Great Britain with the construction of clusters of large offshore wind farms. These clusters can produce large ramping events (i.e. changes in power output) on temporal scales which are critical for managing the power system (30 minute, 60 minute and 4 hours). This study analyses generation data from the Thames Estuary cluster in conjunction with meteorological observations to determine the magnitude and frequency of ramping events and the meteorological mechanism.
\end{abstract}

Over a 4 hour time window, the extreme ramping events of the Thames Estuary cluster were caused by the passage of a cyclone and associated weather fronts. On shorter time scales, the largest ramping events over 30 minute and 60 minute time windows are not associated with the passage of fronts. They are caused by three main meteorological mechanisms; (1) very high wind speeds associated with a cyclone causing turbine cut-out (2) gusts associated with thunderstorms and (3) organised band of convection following a front. Despite clustering offshore capacity, the addition of offshore wind farms has increased the mean separation between capacity and therefore reduced the variability in nationally aggregated generation on high frequency time scales.

Keywords: wind; offshore; variability; ramping; extremes

\subsection{Introduction}

To meet ambitious carbon reduction targets, global renewable energy deployment has expanded dramatically. In the UK, the capacity of wind power has grown steadily from $2.9 \mathrm{GW}$ in 2008 to 17.9 GW by June 2017 [1]. Due to the increasing penetration of wind power, extreme wind power generation events are of growing concern. In particular, ramps in generation provide challenges for the transmission system operator who schedule reserve holding in advance and require long term strategies for system balancing [2]. Consequently, a number of studies have focused on understanding and improving the predictability of wind power ramping events $[3,4,5,6]$.

For the UK, Cannon et al. [7] used wind speed data derived from the MERRA reanalysis dataset to quantify the magnitude and frequency of nationally-aggregated wind generation ramping on time scales of 6 hours and greater based on the 2012 wind farm distribution. However, in recent years there has been a significant change in the distribution of wind farms in the Great Britain [8]. Since 2012, the capacity of offshore wind farms has increased from $2.4 \mathrm{GW}$ to $5.0 \mathrm{GW}$ with much of this capacity spread over a small number of very large wind farms located in clusters. For example, in the Thames Estuary alone there is approximately $1.7 \mathrm{GW}$ of capacity. Drew et al. [3] showed this has led to large 
regional ramps in generation on time scales of minutes to hours as local meteorological phenomena simultaneously impacts production in several large farms. Given the large capacity of the farms, these ramps can present a challenge in maintaining the balance between supply and demand on a national scale, particularly if they are not accurately forecasted.

The problem posed by local ramping events is expected to be exacerbated in the coming years, given the trend for clustering capacity in large offshore wind farms looks set to continue. The latest phase of offshore wind development in the UK, launched in 2009, identified 9 zones within which a number of individual wind farms could be located with a total capacity of over $30 \mathrm{GW}[9,10]$. Consequently, following the construction of the round 3 wind farms the majority of GB wind capacity would be located offshore in clusters of very large wind farms [11, 12].

To improve the performance of operational wind power forecasts there is an increasing need for a clear understanding of the meteorological features responsible for the extreme local ramping events [13]. For example, Trombe et al. [14] showed that high frequency ramping of large Danish offshore wind farms can be associated with heavy rainfall and therefore considered the scope for using data from the rainfall radar to adjust the forecast in real-time if necessary. This study investigates whether such an approach could be applied to ramping events in the Thames Estuary wind farms.

In addition to the problems posed by local ramping events, there are concerns that clustering capacity could lead to an increase in the variability of the nationally aggregated wind generation (i.e. a reversal of some of the smoothing benefits gained by the spatial dispersion of turbines). A number of studies have investigated the reduction in wind power variability due to geographical dispersion of turbines for single European countries. For example, Kubik et al. for Northern Ireland [15], Hurley and Watson for Ireland [16], Hasche for Germany and Ireland [17] and Giebel [18], Landberg [19], Buttler [20] and Huber et al. [21] considered the whole of Europe.

For the UK, Sinden [22] and Earl et al. [23] used wind speed data measured at Met Office surface stations to quantify the inter-annual, seasonal and diurnal variability of UK aggregated wind generation. However, these studies did not consider offshore sites and assumed the distribution of wind capacity matched the distribution of weather stations which can lead to large errors [24]. To address this problem, Cannon et al. [7] used wind speed data derived from the MERRA reanalysis dataset to determine the characteristics of wind power in Great Britain over a 33 year period. The study provides a detailed climatology of ramping on time scales of 6 hours and greater.

Using the approach outlined in Cannon et al. [7], Drew et al. [12] showed that the increased penetration of offshore wind farms has little impact on the ramping of GB-aggregated wind generation on time scales of greater than 6 hours. However, due to the resolution of the model, MERRA reanalysis data cannot be used to determine the high frequency GB-aggregated power swings (minutes to hours) or quantify the magnitude of wind power ramps at high spatial resolutions (below $300 \mathrm{~km}$ ), both of which are important considerations for managing the power system.

In the UK, the electricity market is managed in 30 minute windows, known as settlement periods. For each period, suppliers and generators contract electricity up to 1 hour prior to the delivery time, a cutoff time known as "gate closure". It is then the responsibility of the system operator (National Grid) to take any necessary actions in order to balance the grid within each settlement period. The electricity network in the UK is largely isolated with relatively few interconnectors to neighbouring countries and therefore there is a reliance on large conventional power plants to manage the system. However, these plants generally require a period of notice prior to generation to ramp up, generally assumed to 
be at least 4 hours. To manage the power system, it is therefore important to understand the possible ramps in power that could occur on time scales shorter than the ramp up time of a conventional power plant (4 hours), between gate closure and settlement period ( 1 hour) and from one settlement period to the next (30 minutes).

The aim of this study is to use a 30-minute averaged time series of wind power generation from a number of regions across Great Britain (GB) in 2014 to investigate how the increased penetration of clustered offshore wind capacity has affected the characteristics of generation at high spatial and temporal resolutions. The first section considers the impact on high frequency variability of wind generation on both a national and regional scale, particularly the magnitude of ramping in generation on time scales of less than 4 hours. The second section determines the meteorological causes of extreme regional ramping events using the Thames Estuary as a case study.

\subsection{Datasets and analysis methods}

One of the main challenges when investigating the variability of wind generation in the UK at high spatiotemporal resolutions is the limited availability of suitable data. Actual metered data from the individual wind farms is protected by commercial interests; therefore there is a reliance on nationally aggregated data. However, analysis using this data is unable to quantify the regional power swings or indicate how the variability has been affected by the change in wind farm distribution. Cradden et al. [24] used an hourly 11 year hindcast derived using the Weather Research and Forecasting model (WRF) at $3 \mathrm{~km}$ resolution to assess the variability of generation from 13 different regions in the UK.

This study introduces a new dataset which details the aggregated power output from four offshore clusters (Anglia, Cumbria, N.Wales and Thames) and five onshore regions; Argyll, Ayrshire, Central, Lothian and SSENW (see Figure 1) at 30 min resolution from $1^{\text {st }}$ January 2014 to $31^{\text {st }}$ December 2014 (see Table 1 and Figure 1). The total capacity across the 9 regions is $6.5 \mathrm{GW}$, which is approximately $70 \%$ of the total installed wind capacity of Great Britain.

A number of wind farms have been excluded from the analysis for two reasons (1) they the sole wind farm in a region therefore it was not possible to produce anonymous, aggregated generation data or (2) the data was not of sufficient quality. Despite the reduced number of wind farms, the dataset provides a good representation of the wind resource. For example, the GB-aggregated capacity factor for 2014 was calculated to be $31 \%$, which compares well to the figure of $30.2 \%$ for the full wind farm distribution [25].

\begin{tabular}{|l|l|l|l|}
\cline { 2 - 4 } \multicolumn{1}{c|}{} & $\begin{array}{l}\text { Mean } \\
\text { separation } \\
(\mathrm{km})\end{array}$ & $\begin{array}{l}\text { Number } \\
\text { of farms }\end{array}$ & $\begin{array}{l}\text { Capacity } \\
(\mathrm{GW})\end{array}$ \\
\hline Lothian & 17.3 & 5 & 0.44 \\
\hline N.Wales & $\mathbf{2 6 . 9}$ & $\mathbf{3}$ & $\mathbf{0 . 1 8}$ \\
\hline Cumbria & $\mathbf{3 0 . 7}$ & $\mathbf{5}$ & $\mathbf{1 . 1 7}$ \\
\hline Thames & $\mathbf{3 4 . 5}$ & $\mathbf{4}$ & $\mathbf{1 . 5 4}$ \\
\hline Anglia & $\mathbf{3 8 . 1}$ & $\mathbf{3}$ & $\mathbf{0 . 3 3}$ \\
\hline Central & 60.7 & 11 & 1.22 \\
\hline Ayrshire & 79.3 & 8 & 0.52 \\
\hline Argyll & 89.1 & 6 & 0.30 \\
\hline SSENW & 115.2 & 16 & 0.80 \\
\hline
\end{tabular}


Table 1 Details of the 4 offshore clusters (bold) and the 5 onshore regions. The mean separation is derived using equation 1 based on the wind farms within each region.

\subsection{Spatial separation of capacity}

The addition of offshore wind farms has changed the distribution of capacity in two distinct ways. Firstly, there is an increased concentration of capacity in clusters. For each region the spatial dispersion of the capacity has been quantified in terms of the mean separation per unit MW of capacity, $\mathrm{S}$, as calculated in [12] as:

$$
s=\sum_{i=1}^{N} \frac{c_{i}}{C_{T}}\left(\sum_{j=1}^{N} \frac{c_{j} d_{i j}}{C_{T}}\right)
$$

where $c_{j}$ is the wind farm capacity, $d_{i j}$ is the distance between wind farms, $N$ is the number of wind farms in the region and $C_{T}$ is the total installed capacity of the region. The offshore regions are generally made up of large wind farms clustered together in a relatively small area and consequently have a low separation between units of capacity $(26.9 \mathrm{~km}$ to $38.1 \mathrm{~km})$. In comparison, onshore regions generally consist of spatially dispersed small wind farms therefore the separation of the capacity is larger $(60.7 \mathrm{~km}$ to $115.2 \mathrm{~km})$, with the exception of Lothian $(17.3 \mathrm{~km})$. Secondly, the addition of the offshore regions has changed the geographical location of the generation. Figure 1 shows that all of the onshore zones are located relatively close to each other in Scotland; therefore the mean separation between the onshore capacity is only $168 \mathrm{~km}$. In contrast, all of the offshore clusters are connected to England, and are more geographically dispersed (mean separation of $327.6 \mathrm{~km}$ between the offshore capacity), therefore by combining the onshore and offshore capacity the mean separation between capacity for the GB wind farm distribution increases to $399 \mathrm{~km}$.

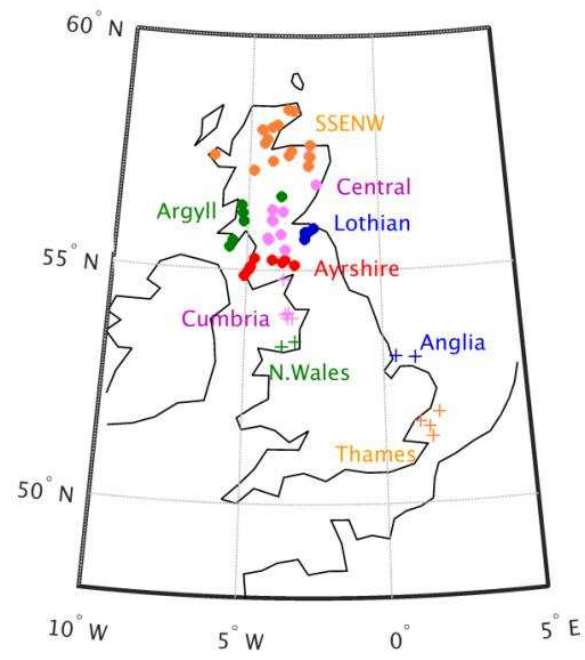

Figure 1 Map of the wind farm distribution used in this study. The onshore and offshore farms are represented by the circles and crosses respectively.

\subsection{Impact of spatial separation on generation characteristics}

To investigate the impact of spatial separation of capacity on wind power variability in Great Britain, the 30-minute averaged time series of aggregated generation for each of the 9 regions have been combined to derive a time series of power output for every possible combination of regions. This ranges from a combination of two regions (36 possibilities) to the single combination of all nine 
regions (GB-aggregate) and therefore amounts to a total of 515 possible wind farm distribution scenarios each with a different number of wind farms and mean separation between capacity. The data are then used to determine the impact of clustering capacity on the high frequency variability of the wind generation.

A range of different metrics have been used to quantify the variability of wind generation. For the purposes of this study a ramp, $\mathrm{R}$, at time, $\mathrm{t}$, is defined as the difference in the power output over a period of time, $\Delta \mathrm{t}$, given by:

$$
R(t)=P(t+\Delta t)-P(t)
$$

where $\mathrm{P}(\mathrm{t})$ is the power output at time, $\mathrm{t}$. Using the 30-minute averaged dataset, a time series of ramps for $\Delta \mathrm{t}=30$ minutes, 60 minutes and 4 hours, has been calculated for each wind farm distribution scenario. The standard deviation, $\sigma$, of each time series is then calculated to quantify the distribution of the ramps for each scenario.

\subsection{Thames Estuary analysis}

Section 3.3 investigates the most extreme ramping events over three time scales (30 minutes, 60 minutes and 4 hours) of a single offshore cluster in order to determine the meteorological mechanisms. The analysis focuses on the offshore wind farms in the Thames Estuary, located approximately 100-200 km east of London, UK. This is the largest of the offshore clusters consisting of 5 individual farms with a total capacity of $1.7 \mathrm{GW}$. Drew et al. [3] presents a detailed analysis of a high frequency ramping event of this cluster which had significant implications on the management of the power system. This study investigates the full range of extreme ramps to determine the meteorological cause.

To determine extreme ramping events the 30 minute averaged time series of the capacity factor of the Thames region (as outlined in section 2.2) has been used. The extreme ramping events for each time window have been defined following a similar method to that outlined in Cutler et al. [6].

- 4 hour ramps: Find all instances where the 30 minute averaged capacity factor changes by more than $40 \%$ within a 4 hour window. Two individual ramps occurring within a 6 hour window of each other are considered the same event.

- 60 minute ramps: After removing the periods of time during which a 4 hour ramp occurs, find the occasions where the 30 minute averaged capacity factor changes by more than $25 \%$ in a 60 minute time window. Two ramps are considered the same event if they occur within 1 hour of each other.

- 30 minute ramps: After removing the periods where either a 4 hour or 60 minute ramp occurs, find the occasions where the 30 minute averaged capacity factor changes by more than $15 \%$ in a 30 minute time window.

To determine the meteorological mechanisms behind extreme ramping events, a number of datasets have been used (Table 2). Firstly, the meteorological conditions in the Thames Estuary region have been determined using 1-minute averaged observations of temperature, wind speed and surface pressure from two nearby Met Office weather stations (shown in Figure 2) and rainfall rate data derived from radar observations for an area of $4884 \mathrm{~m}^{2}$ covering all of the wind farms on a $1 \mathrm{~km}^{2}$ spatial resolution and a 5 minute temporal resolution [26, 27]. On the larger scale, the synoptic scale conditions have been determined using hourly wind fields and surface pressure from Modern-Era Retrospective Analysis for Research and Applications (MERRA) data [28]. 
In addition to determining the meteorological conditions associated with ramps, hourly surface wind field data from MERRA has been used to estimate the aggregated power generation of the wind farms in the region, following the method of Cannon et al. [7]. Firstly, the horizontally gridded surface hourly winds were bi-linearly interpolated to the location of each wind farm. The derived winds were then vertically interpolated to the hub height of the turbines. Finally, the hub-height wind speeds were converted to power output using a transfer function derived from empirical comparisons between the derived wind speeds and recorded wind farm output. The power output was summed over all wind farms to produce an hourly time series of generation of the Thames Estuary cluster.

\begin{tabular}{|l|l|l|l|}
\hline Dataset & Variables & $\begin{array}{l}\text { Temporal } \\
\text { resolution }\end{array}$ & Location \\
\hline $\begin{array}{l}\text { UK Met Office weather } \\
\text { station observations }\end{array}$ & $\begin{array}{l}\text { Air temperature }(\mathrm{C}) \text { at } 1.25 \mathrm{~m} \\
\text { above the ground. } \\
\text { Mean wind speed and maximum } \\
\text { gust at } 10 \mathrm{~m} \text { above the ground } \\
\left(\mathrm{ms}^{-1}\right) . \text { Atmospheric pressure } \\
(\mathrm{hPa}) .\end{array}$ & $\begin{array}{l}\text { 1-minute } \\
\text { Manston }\left(51.346^{\circ} \mathrm{N},\right.\end{array}$ & $\begin{array}{l}\text { Shoeburyness } \\
\left(51.536^{\circ} \mathrm{N}, 0.809^{\circ} \mathrm{E}\right) .\end{array}$ \\
\hline $\begin{array}{l}\text { Met Office rainfall } \\
\text { radar }\end{array}$ & Rainfall rate $\left(\mathrm{mm} \mathrm{hr}^{-1}\right)$ & 5-minute & $\begin{array}{l}\text { Thames Estuary region } \\
\text { (see Figure 2) on } 1 \mathrm{~km}^{2} \\
\text { resolution. }\end{array}$ \\
\hline $\begin{array}{l}\text { MERRA: Modern-Era } \\
\text { Retrospective Analysis } \\
\text { for Research and } \\
\text { Applications }\end{array}$ & $\begin{array}{l}\text { Mean wind speed }\left(\mathrm{ms}^{-1}\right) \text { at } \\
\text { heights of } 2 \mathrm{~m}, 10 \mathrm{~m} \text { and } 50 \mathrm{~m} .^{\text {Surface pressure }(\mathrm{hPa}) .}\end{array}$ & Hourly & $0.667^{\circ}$ global grid. \\
\hline
\end{tabular}

Table 1 Details of the meteorological datasets used in this study.

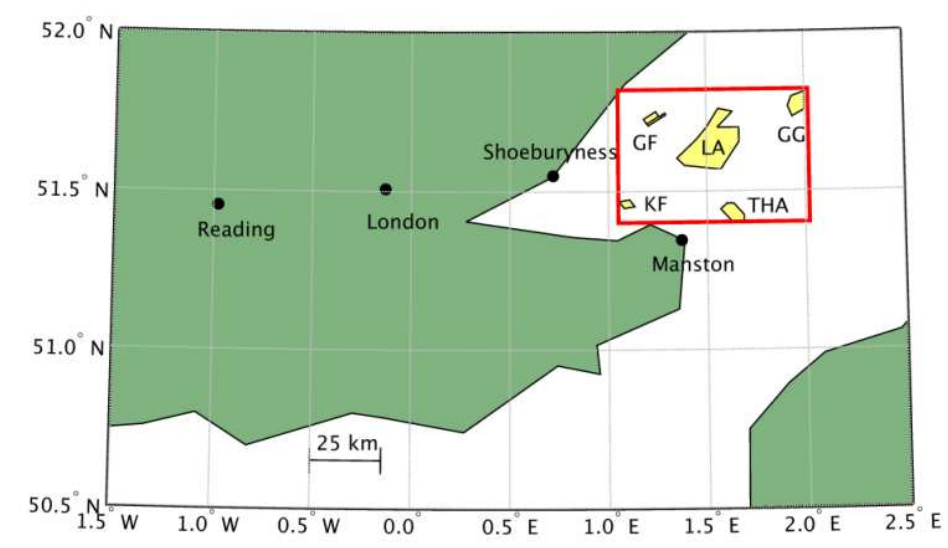

Figure 2 Map showing the location of the 5 wind farms in the Thames Estuary: Greater Gabbard (GG), London Array (LA), Gunfleet Sands (GF), Kentish Flats (KF) and Thanet (THA). The red box indicates the region for which radar rainfall data was obtained. The map also shows the locations of the surface meteorological stations: Manston and Shoeburyness.

\subsection{Results}

The dataset outlined in Section 2 has been used to address a series of questions related to wind power variability. Section 3.1 investigates the impact of the offshore wind farms on the GB-aggregated wind generation characteristics, with a particular emphasis on the impact of changing the separation between capacity and the number of wind farms on the magnitude on the high frequency ramps. Section 3.2 determines the magnitude of regional high frequency power swings for the offshore 
clusters and compares the results to that of the more spatially-dispersed onshore regions. Finally, Section 3.3 quantifies the high frequency ramping of wind farms in the Thames Estuary, the largest offshore cluster and identifies the meteorological mechanism.

\subsection{Impact of clustering capacity on generation variability}

206

This section determines how the magnitude of the ramps in regional wind power varies with two metrics used to define the level of clustering (1) the number of wind farms aggregated and (2) the mean separation between capacity. For all 515 possible wind farm distributions, the time series of power ramps over three time periods ( 30 minutes, 60 minutes and 4 hours) have been determine. The standard deviation of the resulting time series was calculated and is used as a measure of the magnitude of the ramps.
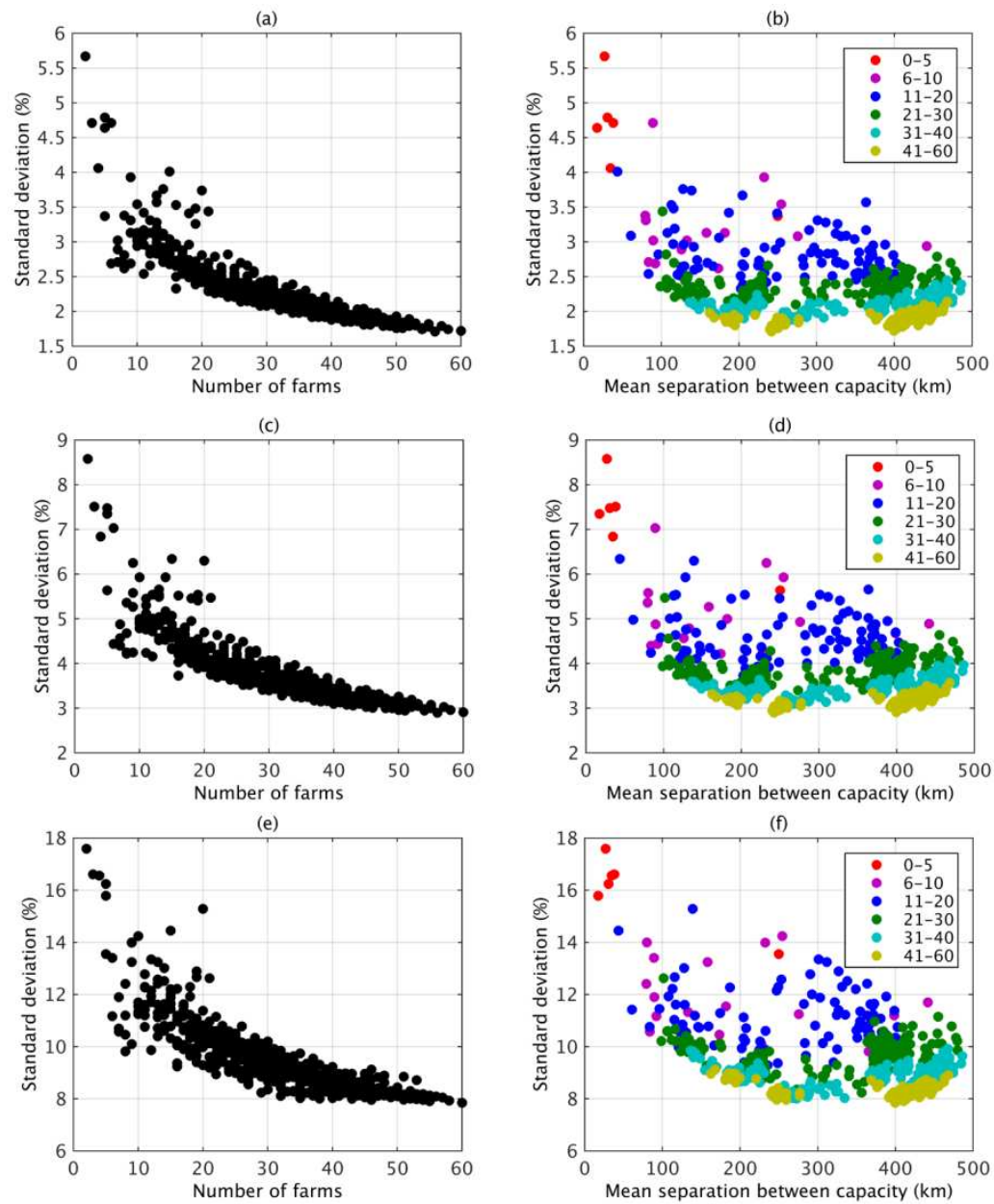

Figure 3 Standard deviation of the power ramps of each of the 515 different wind farm distributions as a function of the number of farms in the distribution and the mean separation between the capacity for three time windows (a)-(b) 30 minutes, (c)-(d) 60 minutes and (e)-(f) 4 hours.

216 For all three time scales, the magnitude of the ramps decreases as the number of wind farms in the distribution increases (see Figures 3(a)-(f)). A large reduction in the standard deviation is shown between 5 and 30 wind farms before levelling off as the number of farms increases further. For example, for the 30 minute ramps the standard deviation decreases from approximately $4.8 \%$ to $2.1 \%$ as the number of wind farms increases from 5 to 25 , but decreases to only $1.9 \%$ as the number of wind farms increases further to 50. However, for all time scales the lowest standard deviation is shown for the largest number of wind farms (i.e. the full GB wind farm distribution). 
This analysis indicates that the number of wind farms aggregated is a useful parameter for estimating the distribution of power swings on time scales of 30 minutes to 4 hours. In comparison, the separation between capacity is not a good indicator of the size of the ramps. For all time scales, increasing the separation (but keeping the number of wind farms the same) has little impact on the size of the ramps (see Figures 3(b), 3(d) and 3(f). For example, for a wind farm distribution which contains 41-60 farms, if the separation between the units of capacity is $200 \mathrm{~km}$ the standard deviation of the 30 minute ramps is between $1.8 \%$ and $2.0 \%$. If the separation were to increase to $400 \mathrm{~km}$ the standard deviation is very similar $(1.7 \%-2.0 \%)$. These results suggest that on the time scales considered, the power ramps of the regions are not well correlated, therefore the magnitude of the aggregated ramps decrease as more and more regions (number of farms) are added, irrespective of any potential change in the separation between capacity.

\subsection{Regional power ramps}

The analysis in section 3.2 has shown that the magnitude of the power ramps of a wind farm distribution is highly dependent on the number of wind farms. The recent trend of concentrating a small number of very large wind farms therefore results in an increase in the magnitude of the local power ramps. Figures 4 to 6 show the distribution of the power ramps for each region in Great Britain in 2014. For all time intervals, the distribution is approximately symmetric with median values close to zero for both the onshore and offshore regions, indicating that positive and negative ramps have a similar distribution.

In general, when considered in terms of a change in capacity factor, the magnitude of the ramps is larger for the offshore clusters for all time scales. Consequently, if the system operator were to hold reserve to protect against a 90th percentile swing, for the onshore regions it would equate to on average $3.8 \%, 6.0 \%$ and $14.5 \%$ of capacity for 30 minutes, 60 minutes and 4 hours respectively. In comparison a similar holding for the offshore regions would equate to an average of $4.8 \%, 7.9 \%$ and $18.9 \%$ of capacity. This is due to the offshore clusters containing a lower number of farms than the onshore zones. As the 4 offshore regions have a similar number of farms, the magnitude of ramps is very similar for all offshore regions- with slight differences in the extreme values. For the onshore regions, there is generally a larger spread in the distributions reflecting the variability in the number of farms across the regions. For example, for Lothian there are a similar number of wind farms to the offshore regions and the standard deviation of the ramps is $4.7 \%, 7.6 \%$ and $17.9 \%$ for 30 minutes, 60 minutes and 4 hours respectively.

When considered in terms of change in power (MW), due to large capacity in Thames Estuary, the ramps of the cluster are larger than all other regions for all time scales (as shown in Figures 4-6 (c)). For example, for the 30 minutes, 60 minutes and 4 hour time window, the maximum ramp in the Thames Estuary is $777 \mathrm{MW}, 886 \mathrm{MW}$ and $1363 \mathrm{MW}$. Power ramps of this magnitude could potentially pose a challenge to those responsible for maintaining a balance between supply and demand on the power system. Accurate meteorological forecasting is critical to decisions made on holding reserve, but can be difficult on such short timescales. Here follows a detailed investigation into the meteorological conditions causing ramps in the Thames Estuary, to inform development of accurate forecasts. 

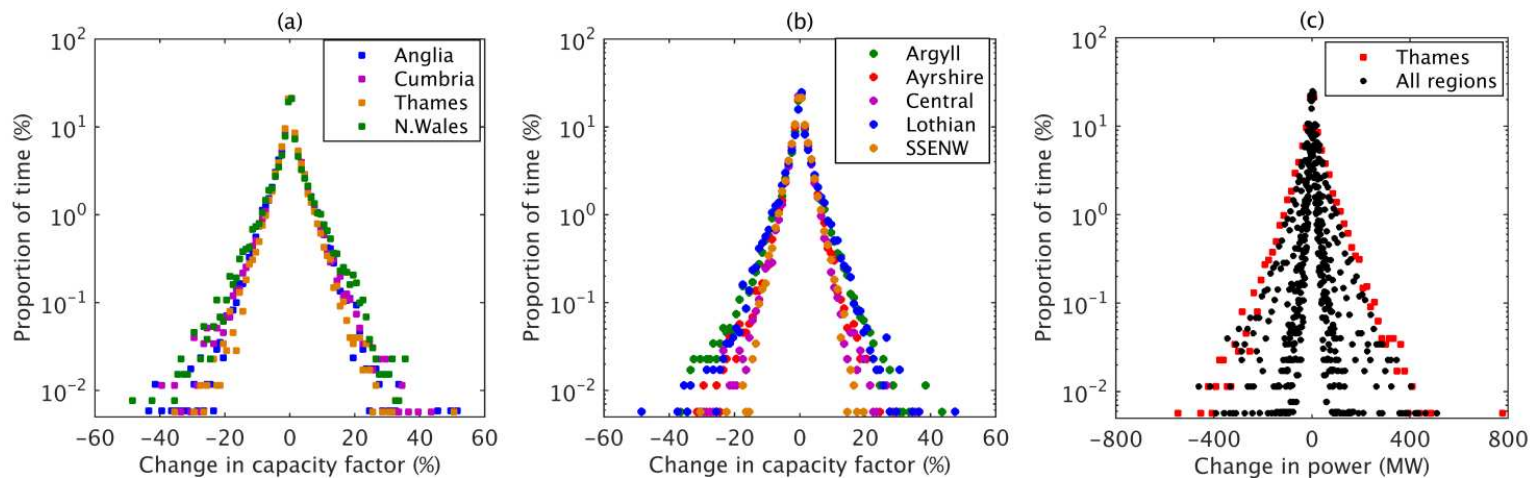

Figure 4 Distribution of the change in capacity factor within a 30 minute time window in 2014 for (a) offshore clusters (b) onshore regions. (c) The ramps expressed in terms of power (MW).
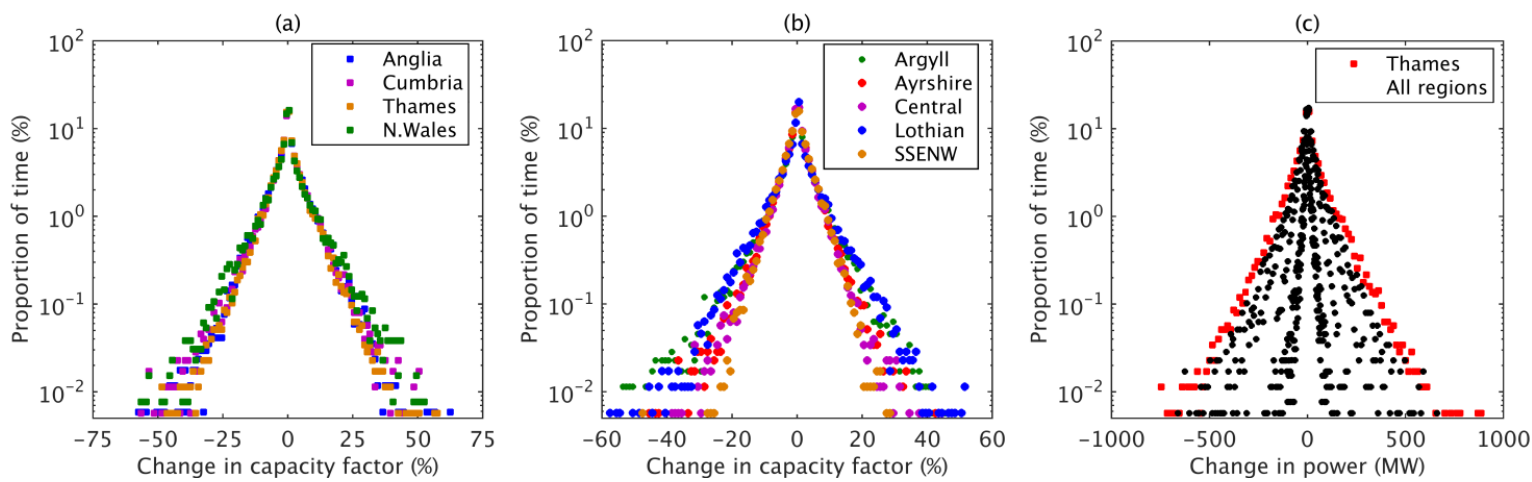

Figure 5 Distribution of the change in capacity factor within a 60 minute time window in 2014 for (a) offshore clusters (b) onshore regions. (c) The ramps expressed in terms of power (MW).
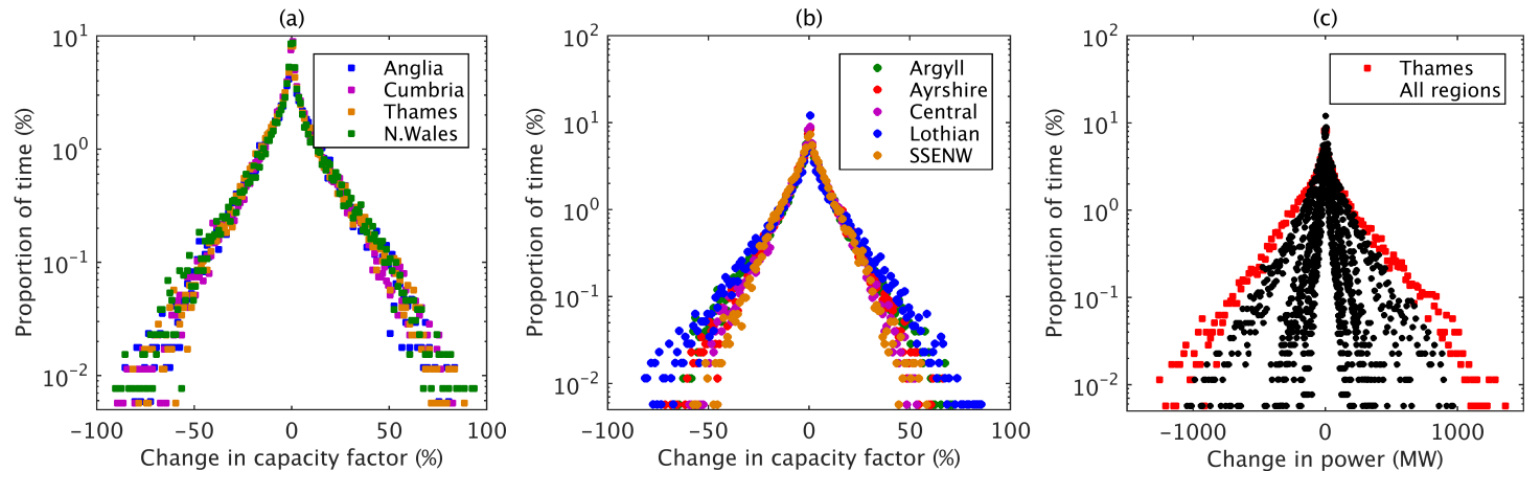

270 Figure 6 Distribution of the change in capacity factor within a 4 hour time window in 2014 for (a) offshore clusters (b) onshore regions. (c) The ramps expressed in terms of power (MW).

\subsection{Thames Estuary ramping}

In Section 3.2 it was shown that the clusters of offshore wind farms can lead to large high frequency regional power ramps. This section analyses the generation data from the Thames Estuary cluster (the largest of the offshore clusters in terms of capacity) in more detail, to identify the extreme ramping events and determine the meteorological drivers. As with the previous sections, the analysis has been completed on three time scales (30 minutes, 60 minutes and 4 hours).

\section{3.3.1 Extreme ramps over a 4-hour time window}

279 Following the method outlined in section 2.3 (the hourly capacity factor changes by more than $40 \%$ over a 4 hour time window), 74 ramp-up events and 69 ramp-down events were identified. Events occurred throughout the year, however a larger proportion occurred in winter (39\% in DJF) than any 
of the other seasons (22\% in MAM, 24\% in JJA and 15\% in SON). The most extreme ramp-up event was $86.2 \%$ which equates to a change in power of $1.3 \mathrm{GW}$ and the most extreme ramp-down was $76.7 \%$ which equates to a change in power of $1.2 \mathrm{GW}$.

For each event, the synoptic meteorological conditions have been investigated using the surface pressure data from MERRA (see figure 7). All of the extreme ramping events on this time scale can be linked to the passage of an extra-tropical cyclone (low pressure system) and the associated weather fronts. For all of the 74 ramp-up events, there is a clear pattern in the surface pressure field. A low pressure system is centred over Iceland and the frontal features stretch south-east across the UK. There is a similar pattern for the ramp-down events however the centre of the low pressure has moved eastwards and the gradient in surface pressure over the UK has weakened. Additionally, the frontal features are now located east of the cluster.

By applying the method developed in Cannon et al. [7], the hourly generation of the Thames Estuary cluster in 2014 has been estimated based on the surface wind field given by MERRA. The derived data have been analysed to determine whether extreme ramping events are captured. MERRA is defined to have captured a ramp if it is at least $75 \%$ of the size of the measured ramp within a \pm 3 hour time window of when it occurred. Based on this criterion, the MERRA derived data captures all 74 ramp-up events and 69 ramp-down events which occurred in the Thames Estuary offshore cluster during 2014. This confirms that the extreme ramping on this time scale is the result of synoptic scale meteorological features which are well reproduced by the reanalysis product.

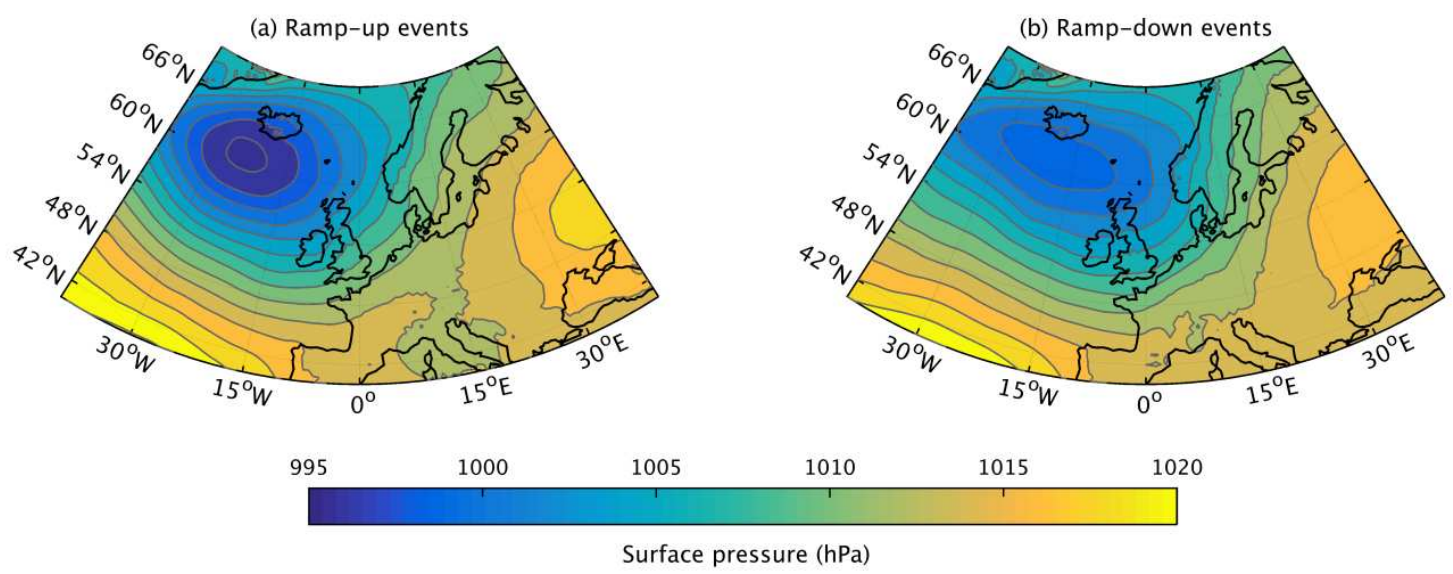

Figure 7 Mean sea level pressure averaged across all (a) 74 ramp-up events and (b) 69 ramp-down events.

\subsubsection{Extreme ramps over a 1-hour time window}

For the full year of measured data, power ramps over a one hour time window have been calculated and the frequency distribution of the ramps is shown in Figure 8 (this is the same data as the Thames curve in Figure 5(a)). The data have then been filtered to remove the periods which contain a 4 hour ramp (identified in section 3.3.1) and the distribution of the filtered ramps is also shown in Figure 8. A comparison of the probability density functions shows the most extreme 60 minute ramping events are the same in both distributions. For the both the filtered and unfiltered datasets the largest rampdown is $-48.8 \%$ and the largest ramp-up event is $57.9 \%$. This indicates that the most extreme 1 hour ramps are not part of a larger scale ramp and are therefore not caused by the passage of low pressure system but by smaller scale meteorological features. 


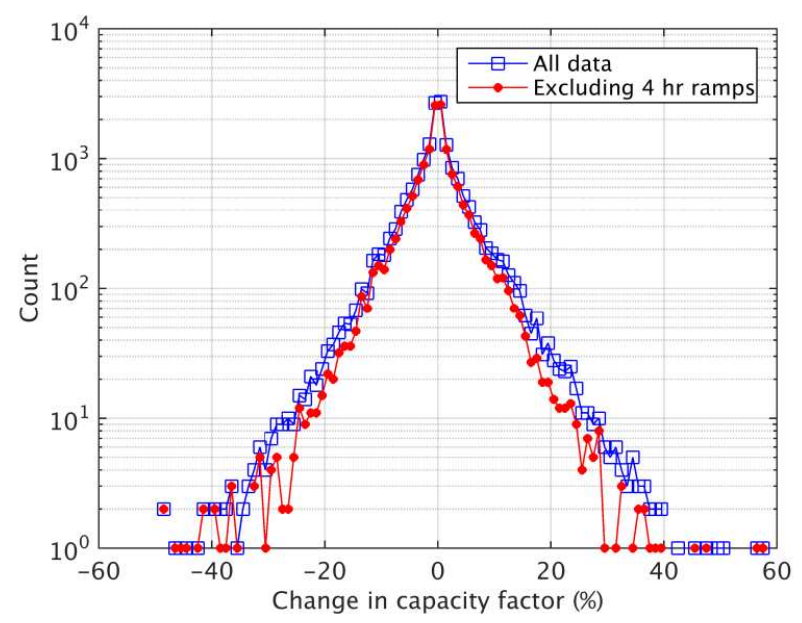

Figure 8 The 60 minute ramps for the Thames Estuary cluster during 2014 using the whole dataset (blue) and then excluding the periods during which a 4 hour ramp occurs.

Using the criteria outlined in section 2.3, $24 \mathrm{x} 1$ hour extreme ramping events have been identified. Further analysis shows, on 10 occasions an extreme ramp-up and ramp-down occurred within 3 hours of each other (as shown in Table 3). These ramps were combined to produce 14 independent events. For each event, the meteorological conditions have been investigated using surface pressure fields from MERRA, observations of surface temperature and wind speed from Met Office weather stations close to the cluster (Manston and Shoeburyness) and rainfall radar data. Based on the meteorological data, 3 main drivers of the extreme ramping on this time scale have been identified; (1) turbine cut-out due to high wind speed conditions (2) outflow or gust fronts from thunderstorms and (3) organised band of convection following a frontal system.

\subsubsection{High wind speed cut-out}

There were 5 ramping events associated with the high wind speed shutdown of turbines. The largest of which occurred on $14^{\text {th }}$ February 2014, when the output of the farms reduced by $44.3 \%$ (i.e. a reduction in power output of $680 \mathrm{MW}$ in 1 hour). All 5 of the cut-out ramping events occurred in winter and are associated with a low pressure system located over the UK. The strong pressure gradient leads to very high wind speeds in the Thames Estuary region. For all of the events, the 1 minute mean wind speed at both Manston and Shoeburyness exceeds $25 \mathrm{~ms}^{-1}$ during the period when generation is reduced.

Three of the five events are characterised by a large reduction in the output as the turbines cut-out followed by a similar sized ramp-up. For example, on $25^{\text {th }}$ January 2014 at 16:00 there was a reduction in capacity factor of the cluster by $28.6 \%$ (see Figure 9) which corresponds to a spike in wind speeds observed in the region (at Manston, the mean wind speed peaked at $35.5 \mathrm{~ms}^{-1}$ at 17:30). Following this, there is a reduction in wind speeds and therefore the turbines start to generate again and therefore there is a ramp-up of $26.7 \%$ at $17: 00$. 


\begin{tabular}{|c|c|c|c|c|c|}
\hline No. & Date & $\begin{array}{c}\text { Ramp-up (\%) } \\
\text { and time }\end{array}$ & $\begin{array}{c}\text { Ramp-down (\%) } \\
\text { and time }\end{array}$ & $\begin{array}{c}\text { Maximum } \\
\text { rainfall rate } \\
\left(\mathrm{mm} \mathrm{hr}^{-1}\right)\end{array}$ & Type \\
\hline 1 & $25 / 01$ & $26.7(17: 00)$ & $-28.6(16: 00)$ & 91 & Cut-out \\
\hline 2 & $12 / 02$ & $38.3(16: 30)$ & $-29.0(14: 00)$ & 15 & Cut-out \\
\hline 3 & $14 / 02$ & & $-44.3(22: 00)$ & 26 & Cut-out \\
\hline 4 & $07 / 03$ & $27.6(20: 00)$ & & 150 & Post-frontal \\
\hline 5 & $23 / 03$ & $32.6(16: 30)$ & $-28.4(17: 30)$ & 71 & Thunderstorms \\
\hline 6 & $24 / 05$ & $26.3(16: 30)$ & & 97 & Post-frontal \\
\hline 7 & $07 / 06$ & $45.4(08: 30)$ & $-48.8(10: 00)$ & 12 & Thunderstorms \\
\hline 8 & $18 / 07$ & $57.9(19: 30)$ & $-42.5(22: 00)$ & 1023 & Thunderstorms \\
\hline 9 & $19 / 07$ & $39.1(04: 30)$ & $-25.4(07: 00)$ & 64 & Thunderstorms \\
\hline 10 & $19 / 07$ & $28.6(19: 30)$ & $-28.4(20: 30)$ & 115 & Thunderstorms \\
\hline 11 & $14 / 08$ & $26.8(14: 30)$ & $-45.9(15: 30)$ & 396 & Thunderstorms \\
\hline 12 & $03 / 11$ & $31.1(13: 30)$ & $-48.8(15: 30)$ & 147 & Post-frontal \\
\hline 13 & $19 / 12$ & $36.9(09: 30)$ & $-39.8(07: 00)$ & 622 & Cut-out \\
\hline 14 & $26 / 12$ & & $-36.3(23: 30)$ & 77 & Cut-out \\
\hline
\end{tabular}

Table 3 Meteorological conditions for the 60 minute ramping events which occurred in the Thames Estuary in 2014 identified using the method outlined in section 2.3 .
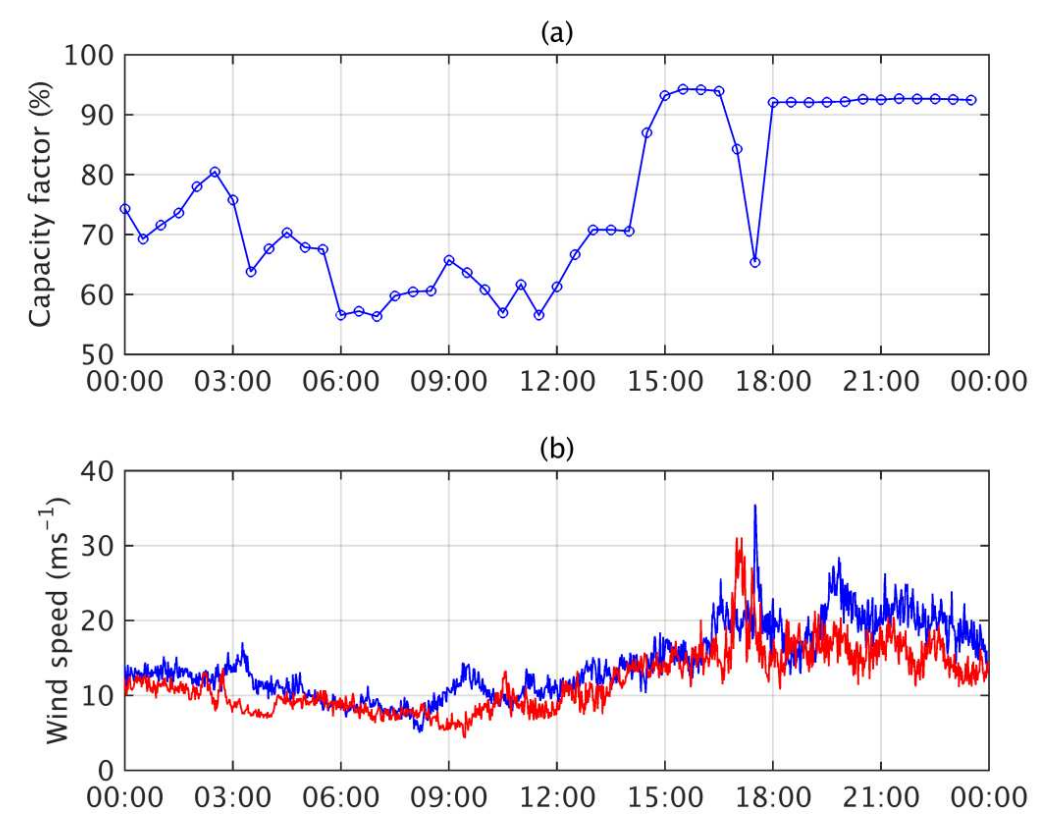

350 Figure 9 Meteorological conditions on 25th January 2014. (a) 30 minute averaged wind power generation of the 351 Thames Estuary cluster (expressed in terms of capacity factor) (b) 1-minute averaged wind speed observations from 352 Manston (blue) and Shoeburyness (red). 
(a)
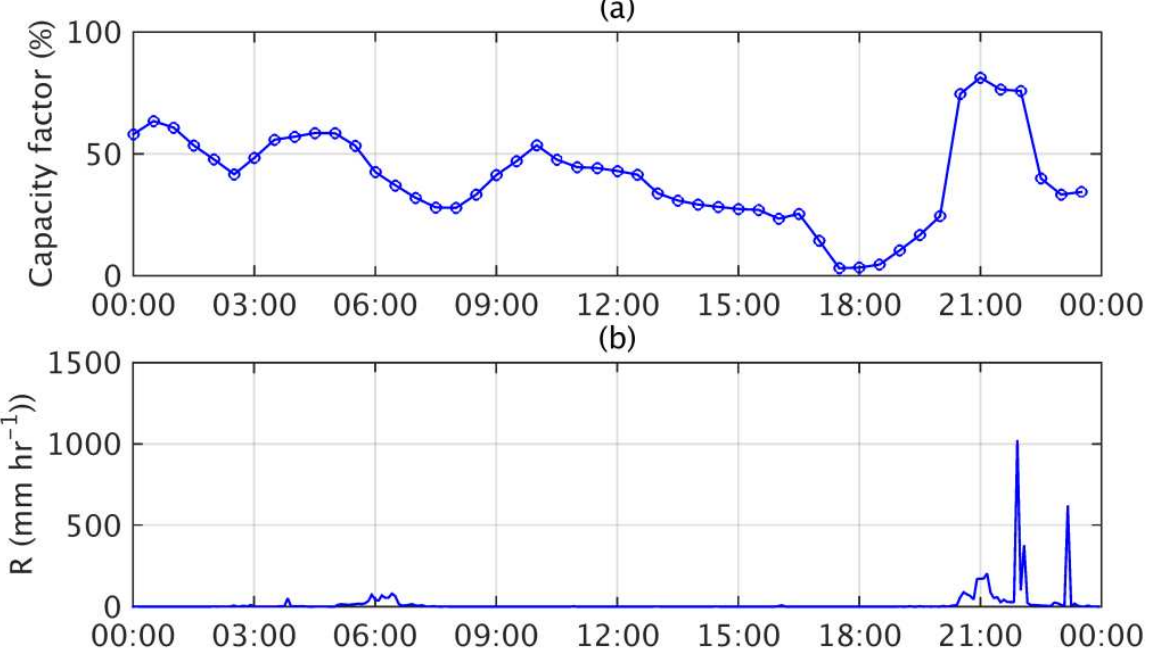

(c)

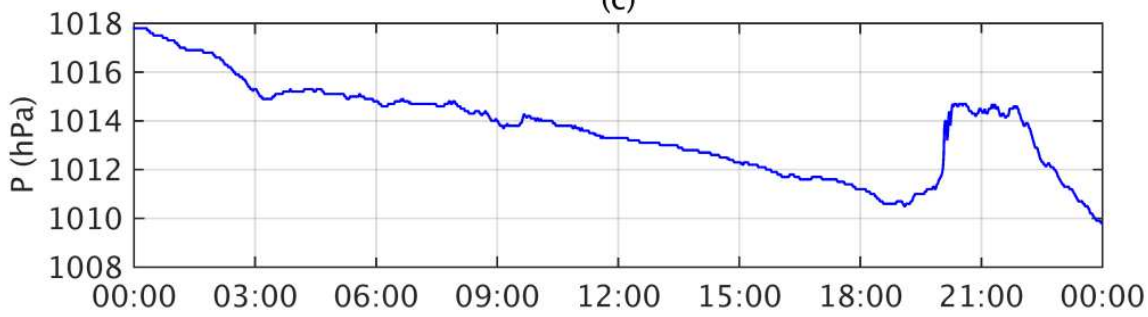

Figure 10 Meteorological conditions for the wind power ramping event on $18^{\text {th }}$ July 2014 . (a) 30 minute averaged wind power generation of the Thames Estuary cluster (expressed in terms of capacity factor) (b) the maximum rainfall rate of any gridbox in the Thames Estuary on a 5 minute resolution and (c) 1-minute surface pressure observations from Manston.

\subsubsection{Thunderstorms}

There were 6 ramping events caused by the wind speed gusts associated with a thunderstorm ( 2 on $19^{\text {th }}$ July 2014), all of which occurred between March and August. For these events the atmospheric conditions are dominated by a high pressure system (anticyclonic) located over the UK and a low pressure system to the south west. Analysis of the meteorological conditions in the Thames Estuary shows that all ramps coincide with other meteorological conditions which are a signature of the thunderstorm, such as a period of heavy rainfall in the region and large fluctuations in temperature. For example, the maximum rainfall rate during the ramp for any $1 \mathrm{~km}$ radar gridbox in the Thames Estuary exceeds $64 \mathrm{~mm} \mathrm{hr}^{-1}$ - for all but one of the ramping events. Furthermore, observations at Manston and Shoeburyness show there is generally sharp drop in temperature during the ramping event.

The largest ramping event associated with a thunderstorm occurred on the $18^{\text {th }}$ July 2014 . At 19:30 the capacity factor of the cluster increased by $57.9 \%$ ( $890 \mathrm{MW}$ in $1 \mathrm{hr}$ ). Figure 10 shows this ramp coincided with very heavy rainfall across the region. The maximum rainfall rate derived from the radar observations was $1023 \mathrm{~mm} \mathrm{hr}^{-1}$ at 22:00. In addition, the surface pressure observed at Manston increased by $4 \mathrm{hPa}$ in a 25 minute period (Figure 10(c)).

\subsubsection{Post-frontal convection}

Three events are caused by a band of increased wind speeds which occur after a front. The elevated wind speeds lead to an increase in power output from the cluster for a short period of time before the 
feature moves away from the region. As with the thunderstorms, there is also a signature of these features in the rainfall data. Figure 11 shows the capacity factor of the Thames Estuary wind farms on $24^{\text {th }}$ May 2014 and the mean rainfall rate across the region. During the morning a weather front moved across the South East of England which led to high wind speeds and heavy rainfall. After the front moved eastwards away from the cluster of farms, their wind generation reduced dramatically, falling from $69.7 \%$ of capacity at $08: 00$ to only $23.7 \%$ at $13: 00$. In the mid-afternoon there was an increase in wind power generation and by 17:00 the output was back up to $62.6 \%$, however this ramp had a short duration and by 20:00 the output had reduced to only $30.0 \%$. Figure 11(b) shows a corresponding ramp in the rainfall in the region.
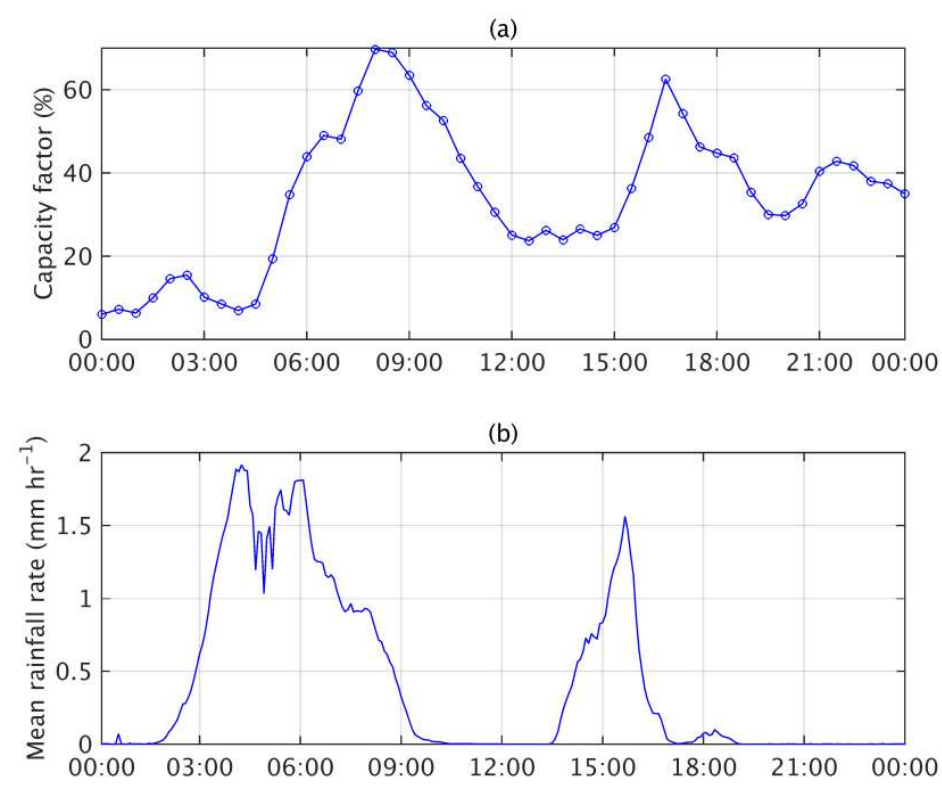

Figure 11 Meteorological conditions for the wind power ramping event and the meteorological conditions on $24^{\text {th }}$ May 2014. (a) The 30 minute averaged wind power generation of the Thames Estuary cluster (expressed in terms of capacity factor) and (b) the mean rainfall rate across the Thames Estuary on a 5 minute resolution.

For the full year of the data the power ramps over a 30 minute time window have been calculated using the method outlined in Section 2.3. The data have then been filtered to remove the periods which correspond to a 4 hour ramp (derived in section 3.3.1). As with the 60 minute ramps, Figure 12 shows that the most extreme 30 minute ramping events are not associated with a larger scale ramp and therefore are not caused by the passage of low pressure system but by a smaller scale meteorological feature.

Using the method outlined in section 2.3, only 630 -minute ramping events have been identified (see Table 4). For each event, the meteorological mechanism has been determined using a range of datasets. Based on the analysis, 4 of the ramps were shown to be associated with the high wind speed 


\begin{tabular}{|c|c|c|c|c|c|}
\hline No. & Date & $\begin{array}{c}\text { Ramp-up (\%) } \\
\text { and time }\end{array}$ & $\begin{array}{c}\text { Ramp-down (\%) } \\
\text { and time }\end{array}$ & $\begin{array}{c}\text { Maximum } \\
\text { rainfall rate } \\
\left(\mathrm{mm} \mathrm{hr}^{-1}\right)\end{array}$ & Type \\
\hline 1 & $03 / 01$ & & $-18.3(15: 30)$ & 9 & Cut-out \\
\hline 2 & $26 / 01$ & & $-16.0(18: 00)$ & 8 & Cut-out \\
\hline 3 & $28 / 01$ & & $-17.4(04: 00)$ & 37 & Cut-out \\
\hline 4 & $01 / 02$ & $15.2(07: 30)$ & & 14 & Cut-in \\
\hline 5 & $19 / 07$ & $21.3(08: 30)$ & & 19 & Thunderstorm \\
\hline 6 & $19 / 07$ & $16.7(12: 00)$ & & 20 & Thunderstorm \\
\hline
\end{tabular}

Table 4 Details of the 30 minute ramping events which occurred in the Thames Estuary in 2014 identified using the method outlined in section 2.3.

407

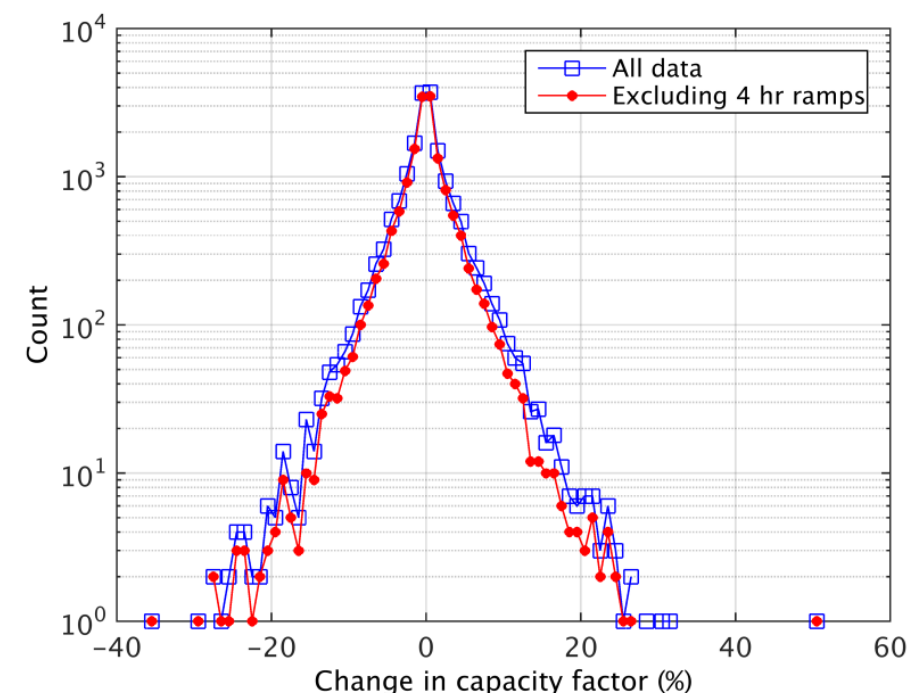

Figure 12 The 30 minute ramps for the Thames Estuary cluster during 2014 using the whole dataset (blue) and then excluding the periods during which a 4 hour ramp occurs.

\subsection{Conclusions}

In recent years there has been a significant change in the distribution of wind capacity in the UK, with the construction of several clusters of very large offshore wind farms. This paper investigates how this change has affected the magnitude of the nationally aggregated and regionalised ramps on temporal scales which are critical for the management of the power system (30 minute, 60 minute and 4 hours). In addition, the extreme high frequency ramps of the largest cluster of offshore wind farms (Thames Estuary) have been investigated in detail to determine the meteorological drivers.

Despite the clustering of capacity in relatively small areas, the addition of the offshore wind farms reduces the high frequency variability of nationally aggregated generation. This study has used two key parameters to quantify the level of clustering; (1) number of wind farms in the region (2) mean separation between capacity. The level of the variability has been considered in terms of the magnitude of the power ramps on the three timescales which are of importance for system management (30 minutes, 60 minutes and 4 hours). For this metric, the magnitude of the variability was highly correlated to the number of wind farms aggregated. As the number of wind farms in the distribution increases, the magnitude of the ramps decreases. This reduction is particularly large between 5 and 25 wind farms before levelling off as the number of farms increases further. In contrast, the mean separation between capacity had little impact on the magnitude of the power swings. In fact, keeping the number of wind farms fixed but changing the separation has a negligible impact on the standard deviation of the distribution of the power swings. These results show that the ramps on these time scales in the different regions are not correlated; therefore aggregating the regions leads to a smoothing effect. 
As the magnitude of the high frequency power swings are highly dependent on the number of wind farms, the recent trend in Great Britain for clustering capacity in a small number of very large wind farms results in an increase in the local power swings. For example, if the system operator were to hold reserve to protect against a $90^{\text {th }}$ percentile swing, for the onshore regions in 2014 it would equate to on average $3.8 \%, 6.0 \%$ and $14.5 \%$ of capacity for 30 minutes, 60 minutes and 4 hours respectively. In comparison, a similar holding for the offshore regions would equate to an average of $4.8 \%, 7.9 \%$ and $18.9 \%$ of capacity. Consequently, for clusters with high levels of capacity this could lead to very large ramps in power. For example, for the Thames Estuary, an $18.9 \%$ ramp equates to a change in power of $290 \mathrm{MW}$. This effect would be exacerbated in the future with the development of even larger clusters (e.g. Dogger Bank which could have a capacity in excess of $4 \mathrm{GW}$ ).

The meteorological conditions leading to extreme high frequency ramping of an offshore cluster have been investigated in more detail using the Thames Estuary as a case study. Over a 4 hour time window, the largest ramp in capacity factor was $86.2 \%$ (which equates to a power swing of $1.3 \mathrm{GW}$ ). This, along with the other extreme 4 hour ramping events was caused by the passage of a cyclone and the associated weather fronts. On shorter time scales, the largest ramping events over 30 minute and 60 minute time windows are not associated with the passage of fronts. They are caused by three main meteorological mechanisms; (1) very high wind speeds associated with a cyclone causing turbine cutout (2) gusts associated with thunderstorms and (3) organised band of convection following a front.

To minimise the balancing costs associated with the extreme high frequency ramping events the meteorological features need to be captured by the wind power forecast. Drew et al. [3] has shown that high resolution ensemble models are able to capture the elevated wind speed associated with postfrontal convection. However, the timing and location of the feature may not be exactly correct. This study has shown that this problem could potentially be addressed by considering the use of real time meteorological observations, such as data from the rainfall radar to adjust the forecast in real-time if necessary.

\section{Acknowledgements}

This work was funded by National Grid via the Network Innovation Allowance (NIA_NGET0128). The authors would particularly like to thank David Lenaghan (National Grid) for helpful advice throughout this project and the aggregated wind farm generation data used in this paper. Thanks also to Dr Rob Thompson from the University of Reading for his assistance with the radar rainfall data.

\section{References}

1. Department for Business, Energy and Industrial Strategy (2017). Energy Trends June 2017. Available from https://www.gov.uk/government/statistics/energy-trends-june-2017

2. Heptonstall, P., Gross, R. and Steiner, F. (2016). The costs and impacts of intermittency- 2016 update. UK Energy Research Centre's Technology and Policy Assessment function.

3. Drew, D.R., Barlow, J. F., Coker, P.J., Frame, T., and Cannon, D.J, (2017) The importance of forecasting regional wind power ramping: A case study for the UK. Renewable Energy, 114, pp 1201-1208.

4. Potter, C. W., Grimit, E., \& Nijssen, B. (2009). Rapid Ramp Event Forecast Tool. IEEE Power systems Conference (pp. 1-5). Seattle, Washington. 
5. Bossavy, A., Girard, R., \& Kariniotakis, G. (2013). Forecasting ramps of wind power production with numerical weather prediction ensembles. Wind Energy, (February 2012), 5163. doi:10.1002/we

6. Cutler, N., Kay, M., Jacka, K., \& Nielsen, T. S. (2007). Detecting, Categorizing and Forecasting Large Ramps in Wind Farm Power Output Using Meteorological Observations and WPPT. Wind Energy, (July), 453-470. doi:10.1002/we

7. Cannon, D. J., Brayshaw, D. J., Methven, J., Coker, P. J., \& Lenaghan, D. (2015). Using reanalysis data to quantify extreme wind power generation statistics: A 33 year case study in Great Britain. Renewable Energy, 75, 767-778. doi:10.1016/j.renene.2014.10.024

8. Department of Energy and Climate Change (2013). UK renewable energy roadmap- update 2013. Retrieved from https://www.gov.uk/government/publications/uk-renewable-energyroadmap-second-update.

9. RenewableUK. UK Wind Energy Database

(UKWED) http://www.renewableuk.com/en/renewable-energy/wind-energy/uk-wind-energydatabase/index.cfm (accessed June 2017).

10. Higgins, P., \& Foley, A. The evolution of offshore wind power in the United Kingdom. (2014) Renewable and Sustainable Energy Reviews 37, 599-612. doi:10.1016/j.rser.2014.05.058.

11. National Grid. UK Future energy scenarios. Retrieved from http://www2.nationalgrid.com/mediacentral/uk-press-releases/2013/national-grid-s-uk-futureenergy-scenarios-2013/ 2013.

12. Drew, D., Cannon, D., Brayshaw, D., Barlow, J., \& Coker, P. (2015). The Impact of Future Offshore Wind Farms on Wind Power Generation in Great Britain. Resources, 4(1), 155-171. doi:10.3390/resources4010155

13. Vincent, C. L., Pinson, P., \& Giebel, G. (2010). Wind fluctuations over the North Sea. International Journal of Climatology, 1595(June 2010), n/a-n/a. doi:10.1002/joc.2175]

14. Trombe, P., Pinson, P., Vincent, C., Bøvith, T., Cutululis, N. A., Draxl, C., Giebel, G., et al. (2013). Weather radars - the new eyes for offshore wind farms? Wind Energy, vol 17, no. 11, pp. 1767-1787, doi:10.1002/we

15. Kubik, M. L., Brayshaw, D. J., Coker, P. J., \& Barlow, J. F. (2013). Exploring the role of reanalysis data in simulating regional wind generation variability over Northern Ireland. Renewable Energy, 57, 558-561. doi:10.1016/j.renene.2013.02.012

16. Hurley and Watson (2002). An assessment of the expected variability and load following of a large wind penetration in Ireland. In proceedings of Global Wind Power Conference. Paris, France.

17. Hasche, B. (2010). General statistics of geographically dispersed wind power. Wind Energy, (April), 773-784. doi:10.1002/we330-342. 
18. Giebel, G. (2001). On the benefits of distributed generation of wind energy in Europe. University of Oldenburg.

19. Landberg, L. (2007). The availability and variability of the european wind resource. International Journal of Solar Energy, 18(4), 313-320. doi:10.1080/01425919708914326

20. Buttler, A., Dinkel, F., Franz, S., \& Spliethoff, H. (2016). Variability of wind and solar power - An assessment of the current situation in the European Union based on the year 2014. Energy, 106, 147-161. doi:10.1016/j.energy.2016.03.041

21. Huber, M., Dimkova, D., \& Hamacher, T. (2014). Integration of wind and solar power in Europe: Assessment of flexibility requirements. Energy, 69, 236-246. doi:10.1016/j.energy.2014.02.109

22. Sinden, G. (2007). Characteristics of the UK wind resource: Long-term patterns and relationship to electricity demand. Energy Policy, 35(1), 112-127. doi:10.1016/j.enpol.2005.10.003

23. Earl, N., Dorling, S., Hewston, R., \& Von Glasow, R. (2013). 1980-2010 Variability in U.K. Surface Wind Climate. Journal of Climate, 26(4), 1172-1191. doi:10.1175/JCLI-D-1200026.1

24. Cradden, L., Restuccia, F., Hawkins, S., \& Harrison, G. (2014). Consideration of wind speed variability in creating regional aggregate wind power time series. Resources, 3(1), 215-234. doi:10.3390/resources3010215

25. Department of Energy and Climate Change. Digest of United Kingdom Energy Statistics 2015; https://www.gov.uk/government/collections/digest-of-uk-energy-statistics-dukes, 2015

26. Met Office (2003): Met Office Rain Radar Data from the NIMROD System. NCAS British Atmospheric Data Centre, http://catalogue.ceda.ac.uk/uuid/82adec1f896af6169112d09cc1174499

27. UK Meteorological Office. Met Office integrated data archive system (MIDAS) land surface station data (1853-current) NCAS British Atmospheric Data Centre. Available from http://badc.nerc.ac.uk/

28. Rienecker, M. M., Suarez, M. J., Gelaro, R., Todling, R., Bacmeister, J., Liu, E., Bosilovich, M. G., et al. (2011). MERRA: NASA's Modern-Era Retrospective Analysis for Research and Applications. Journal of Climate, 24(14), 3624-3648. doi:10.1175/JCLI-D-11-00015.1. 
Figure 1

Click here to download high resolution image

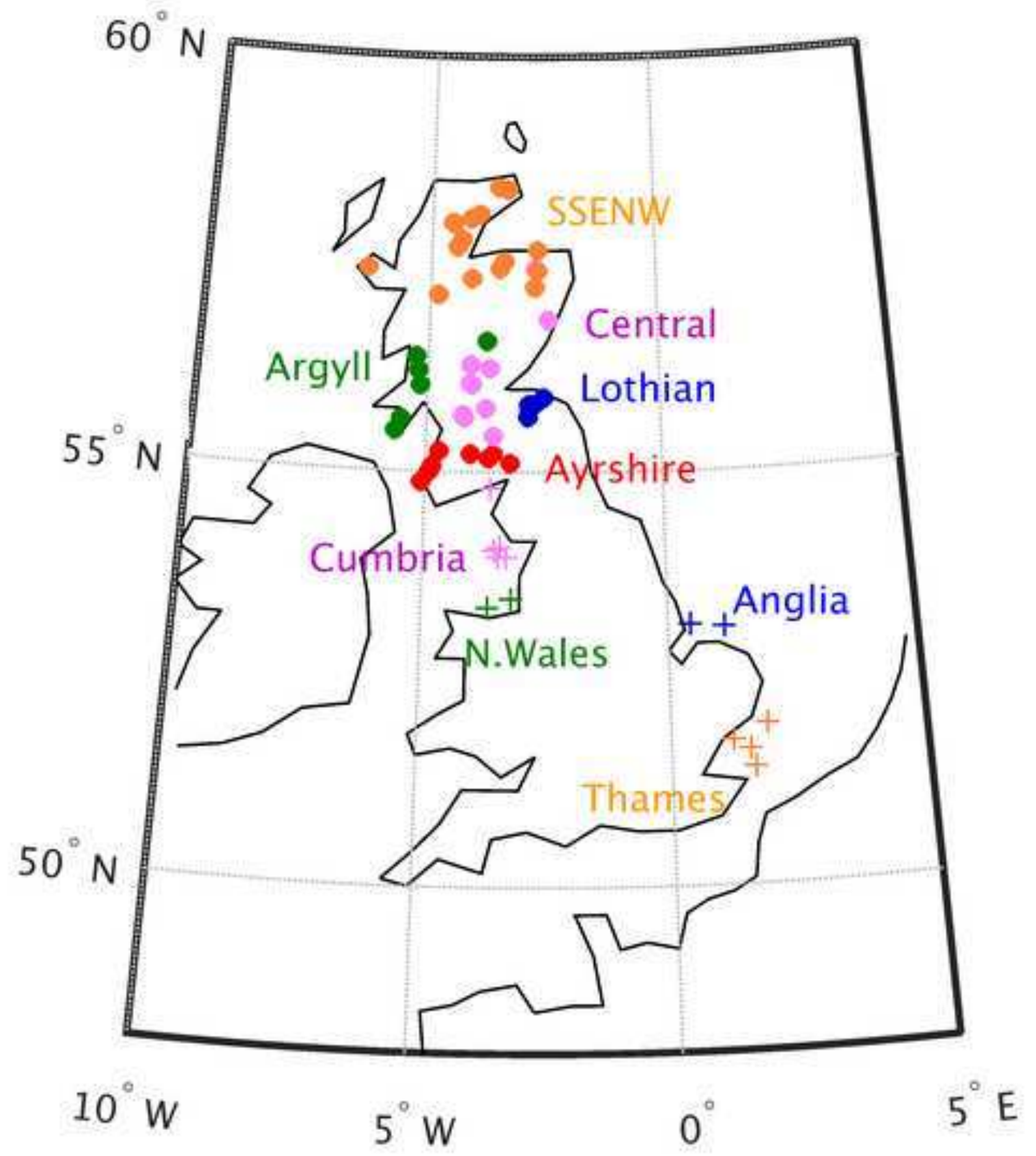


Click here to download high resolution image

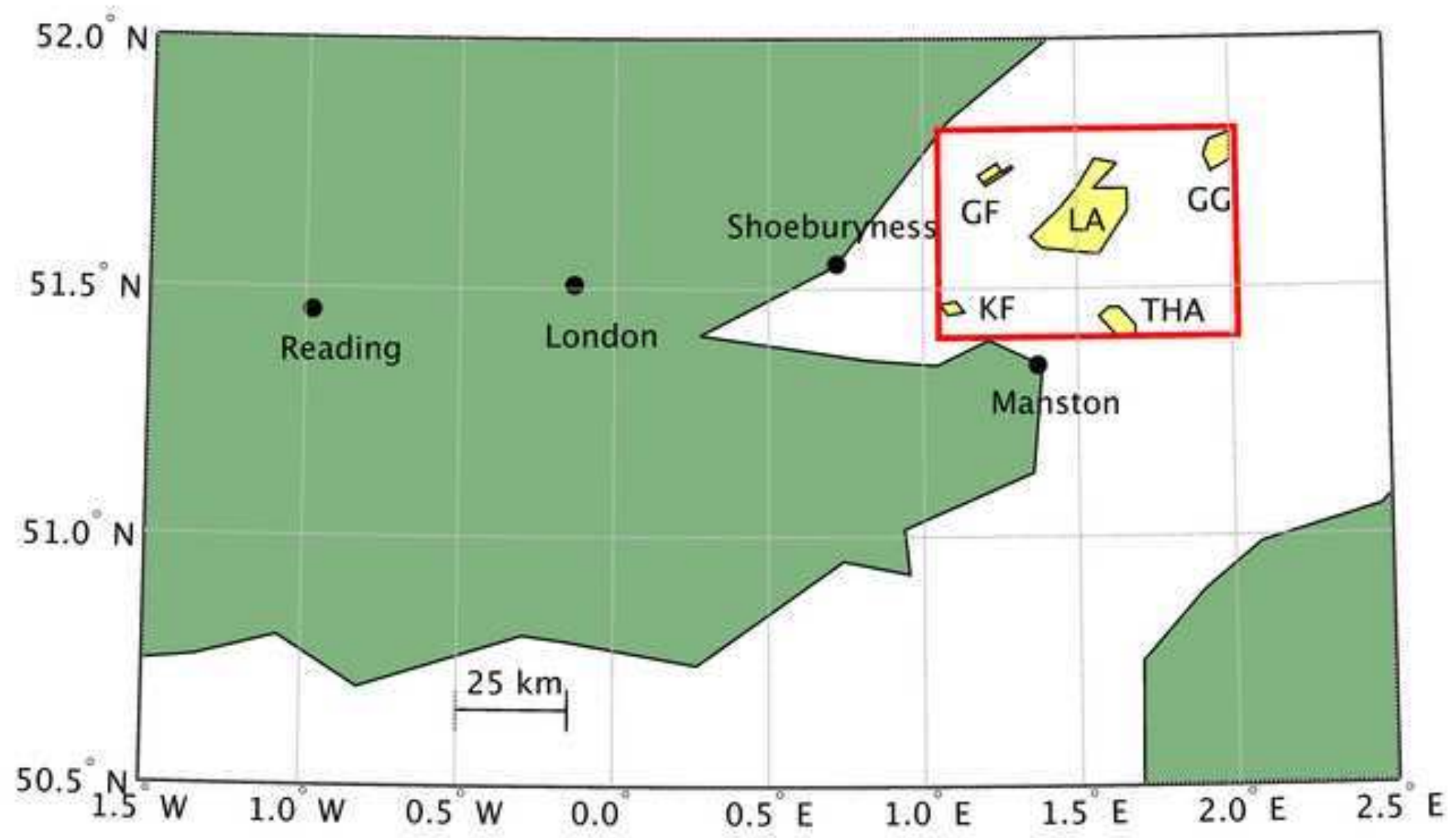


Figure 3

Click here to download high resolution image

(a)

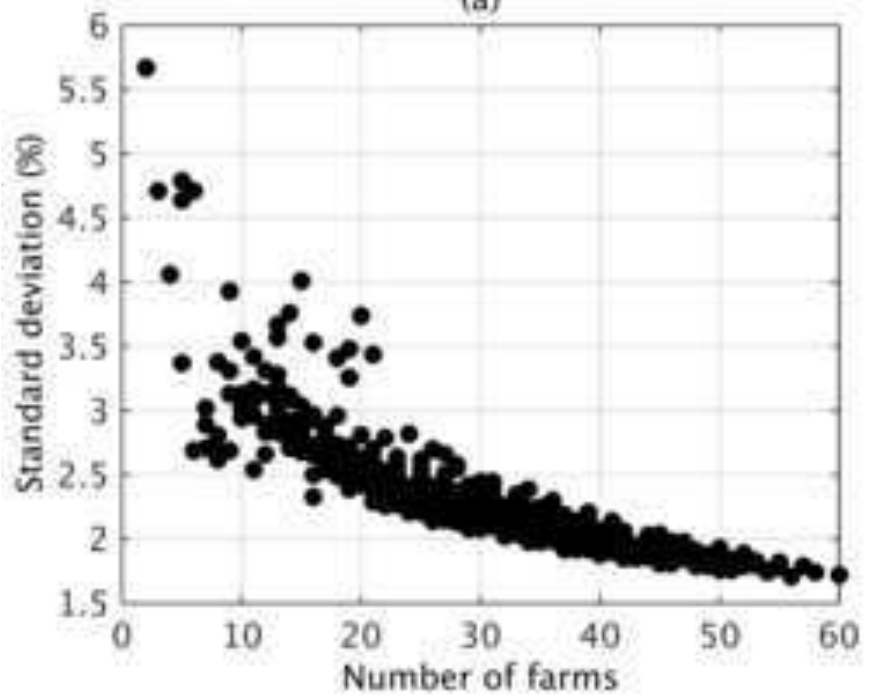

(c)

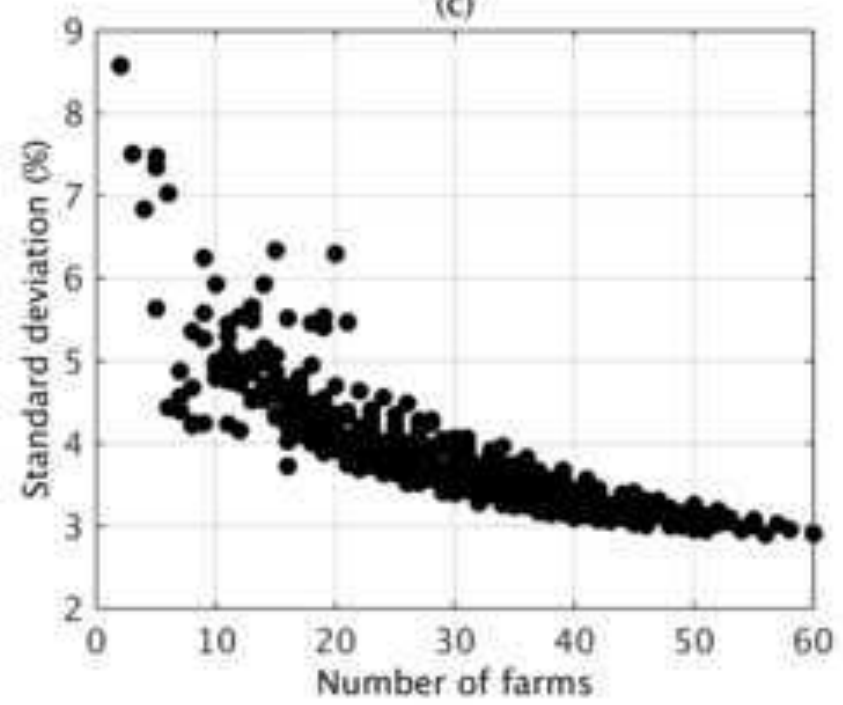

(e)

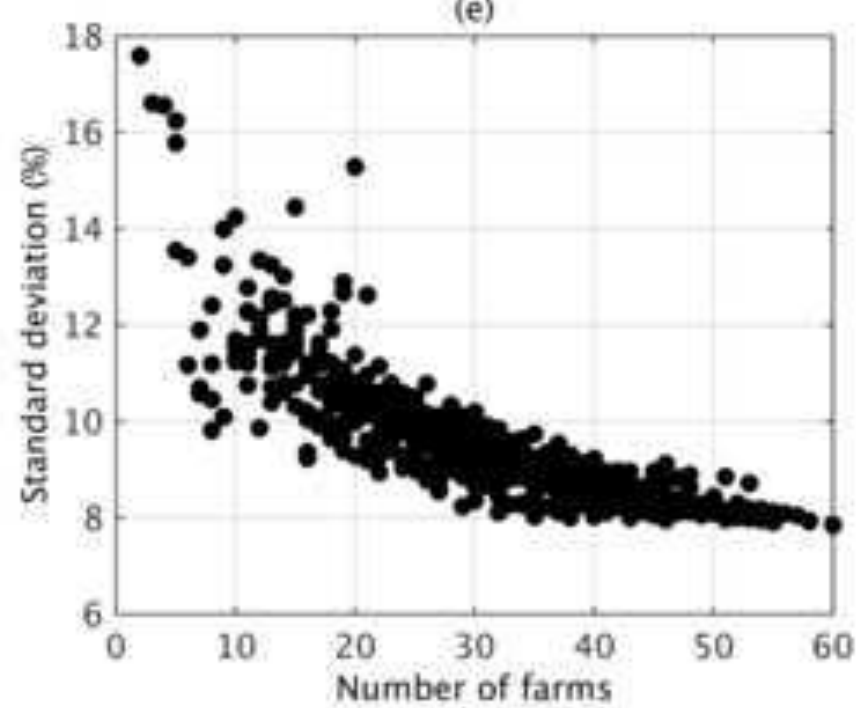

(b)

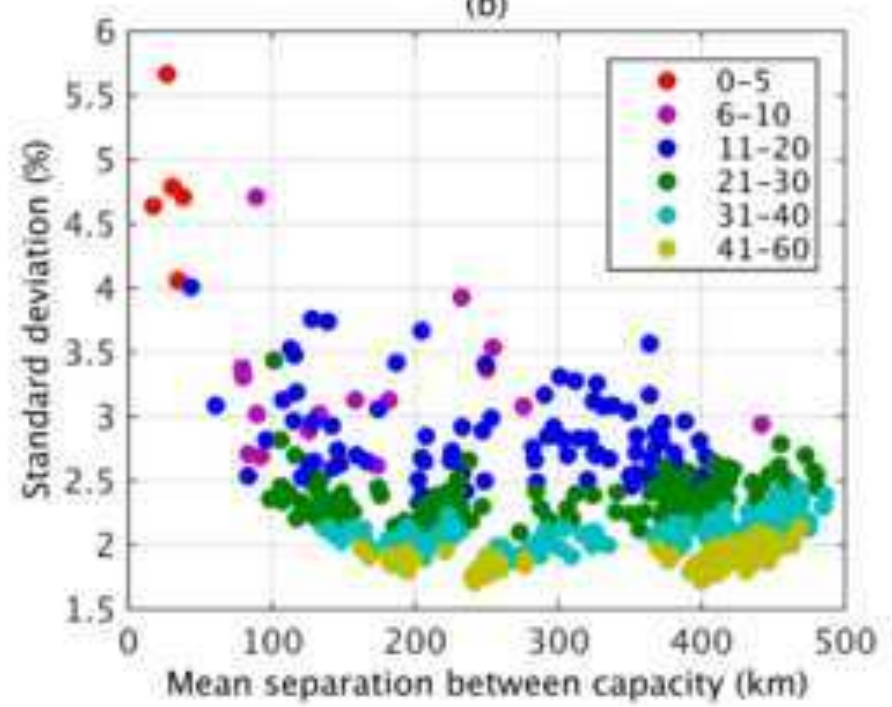

(d)

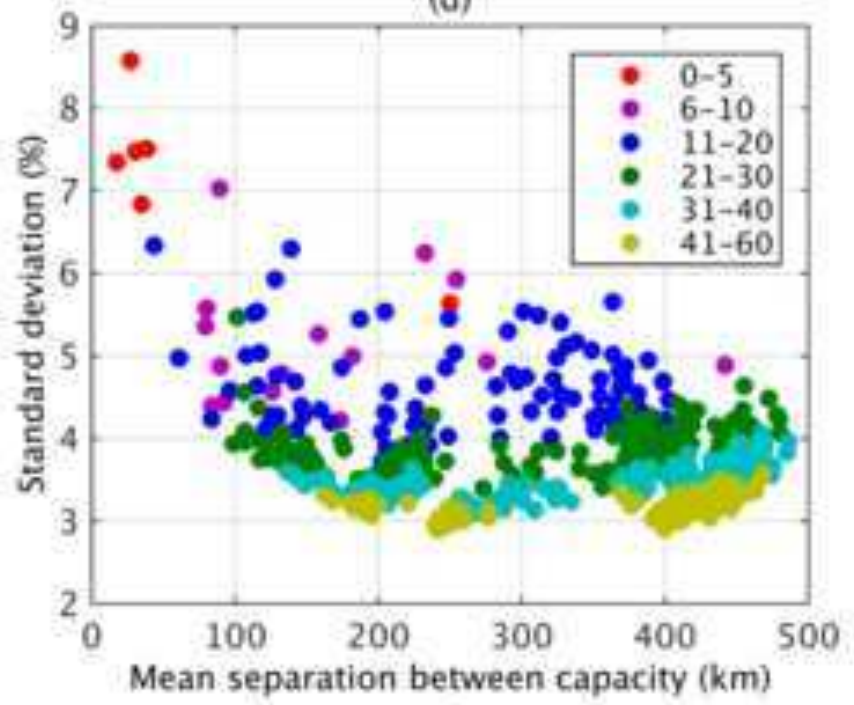

(f)

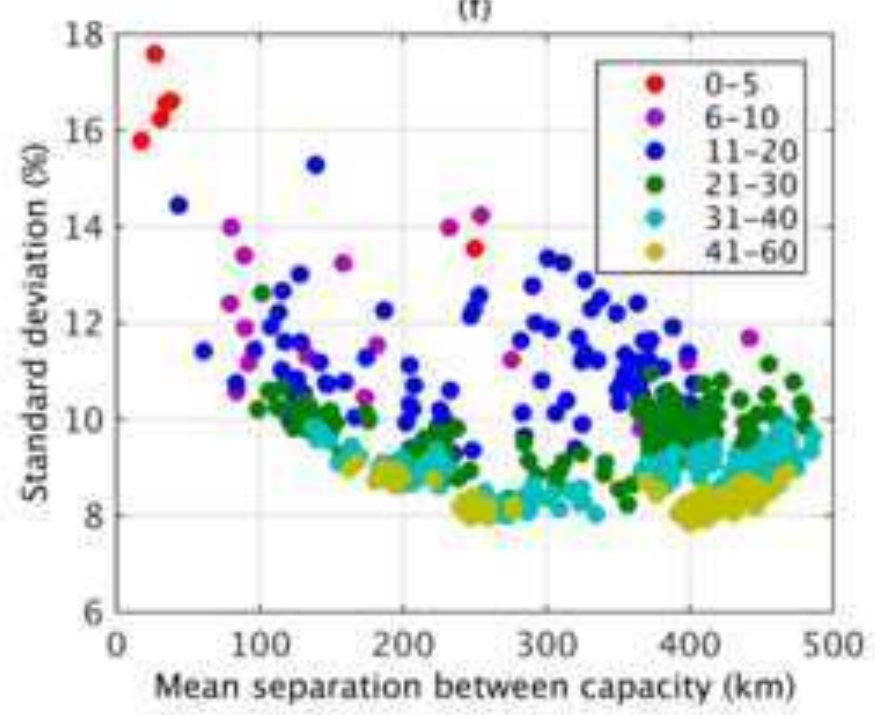


(a)

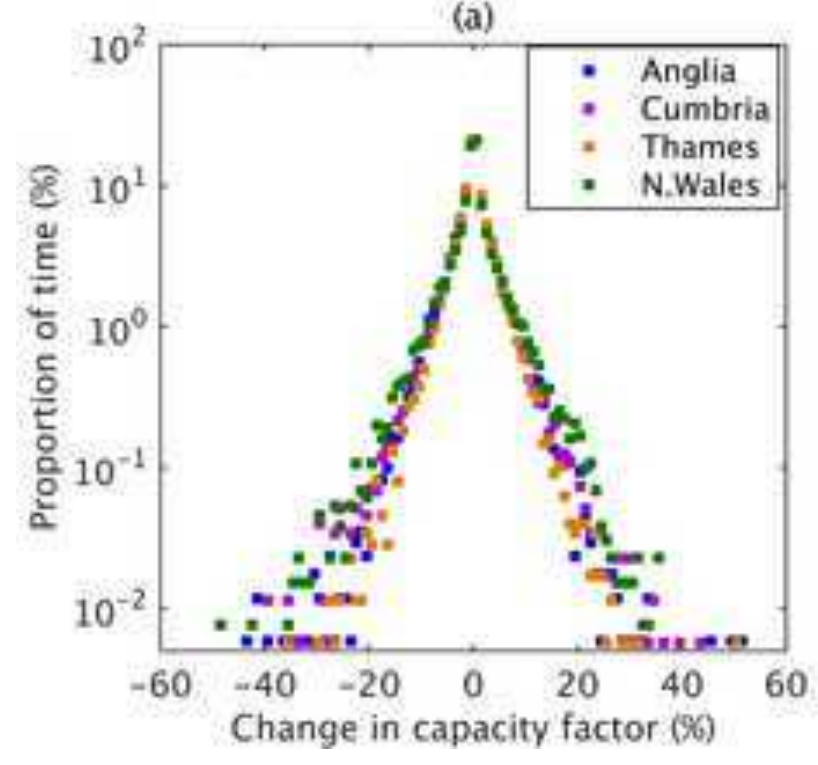

(b)

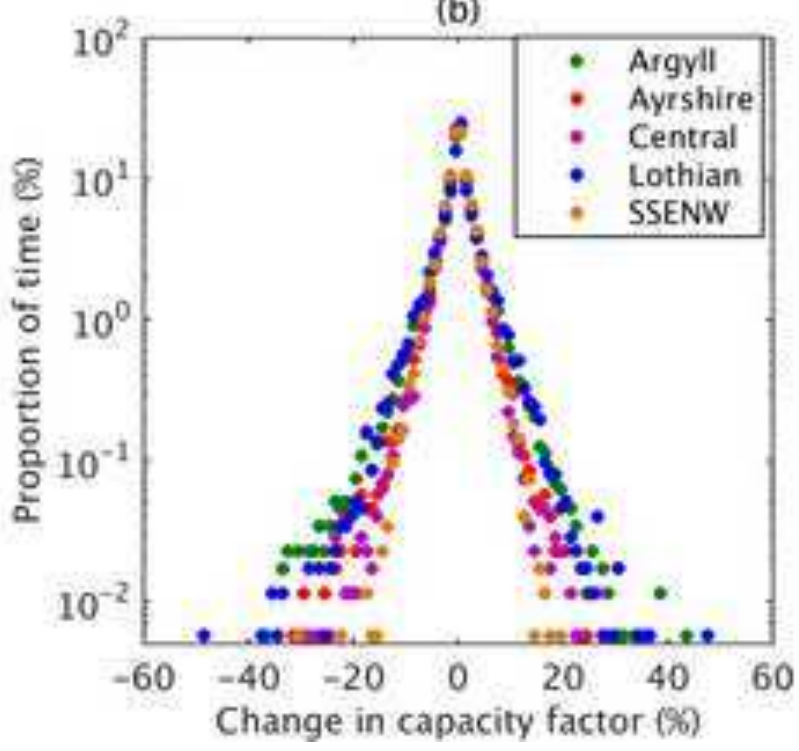

(c)

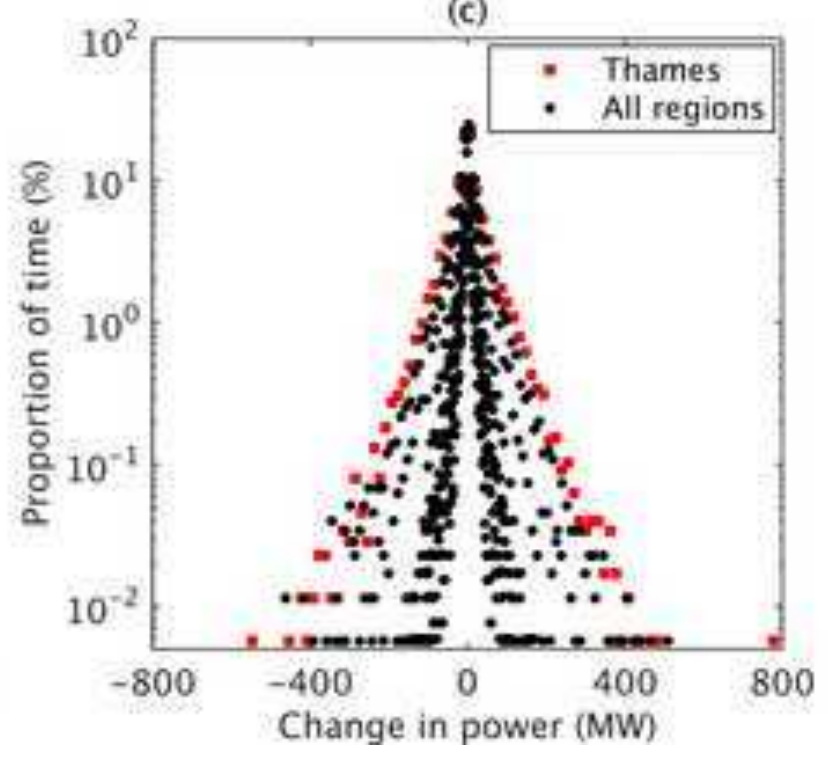



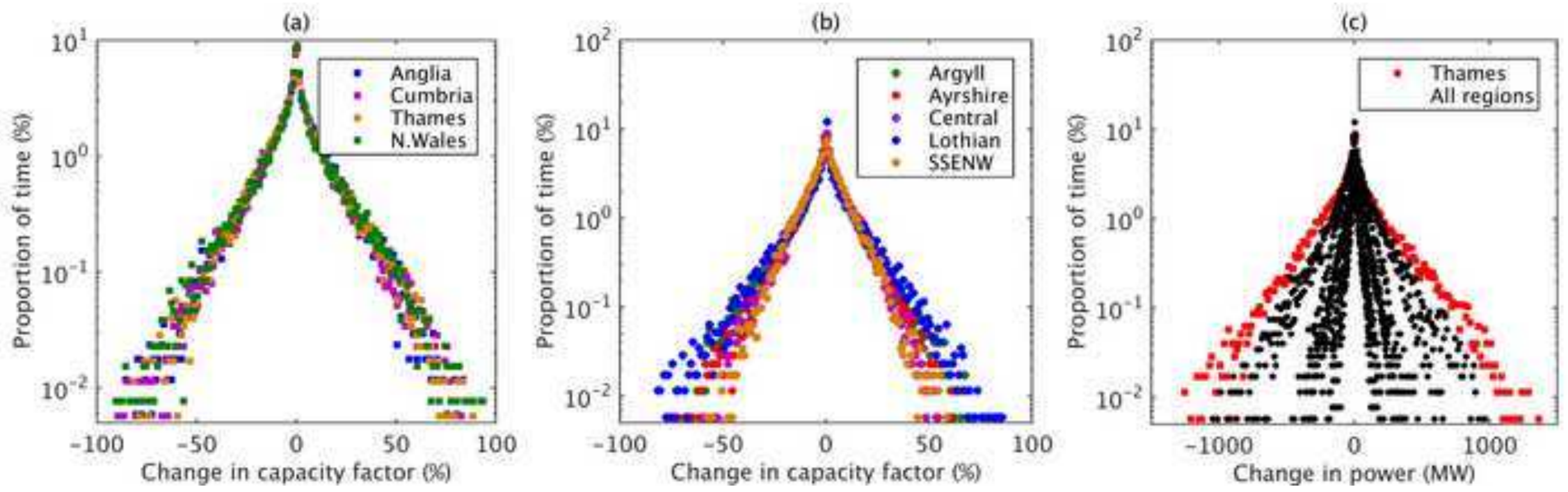
(a)

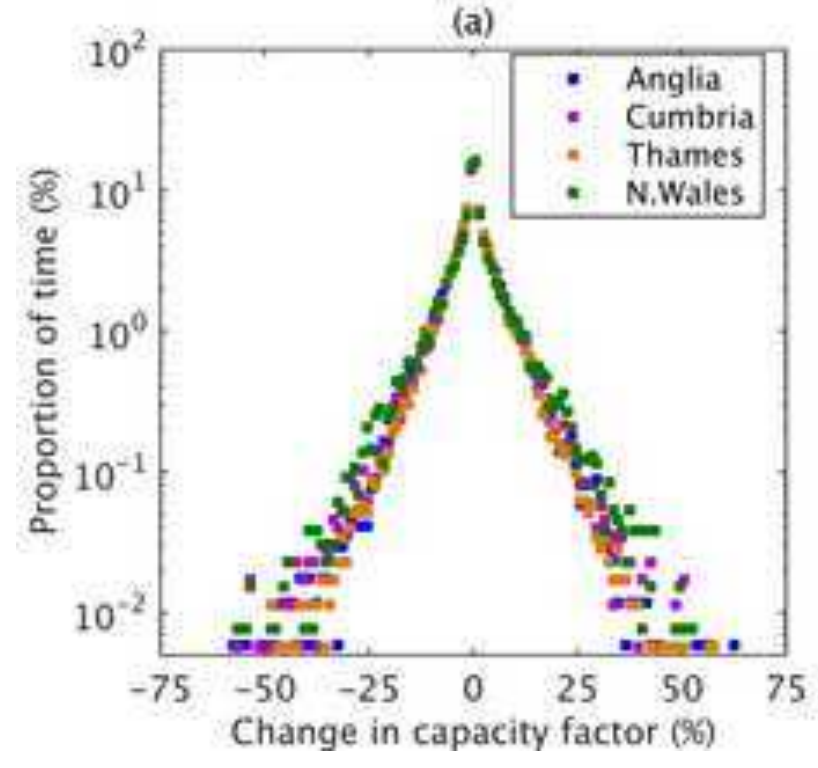

(b)

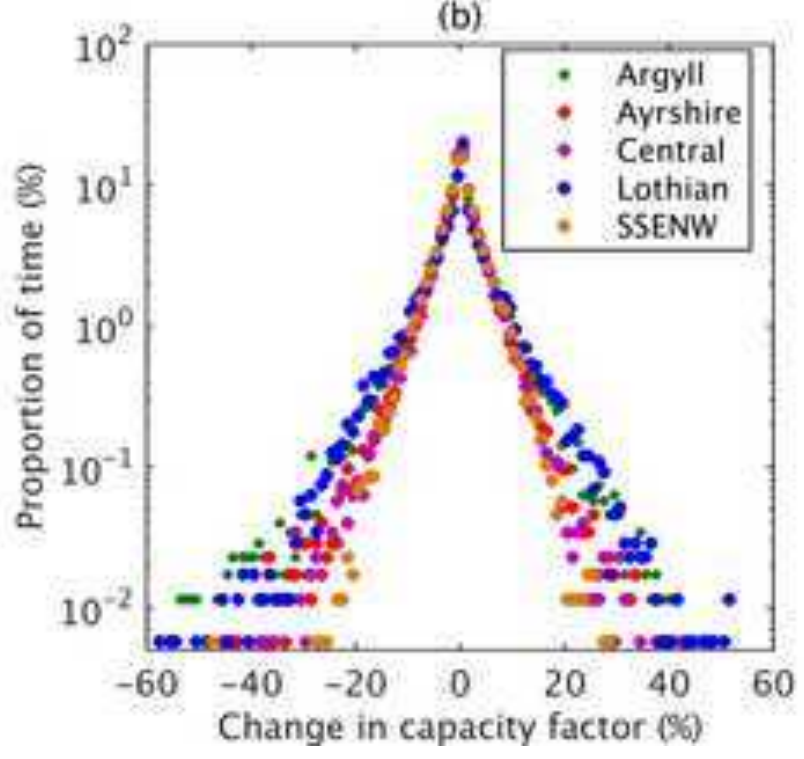

(c)

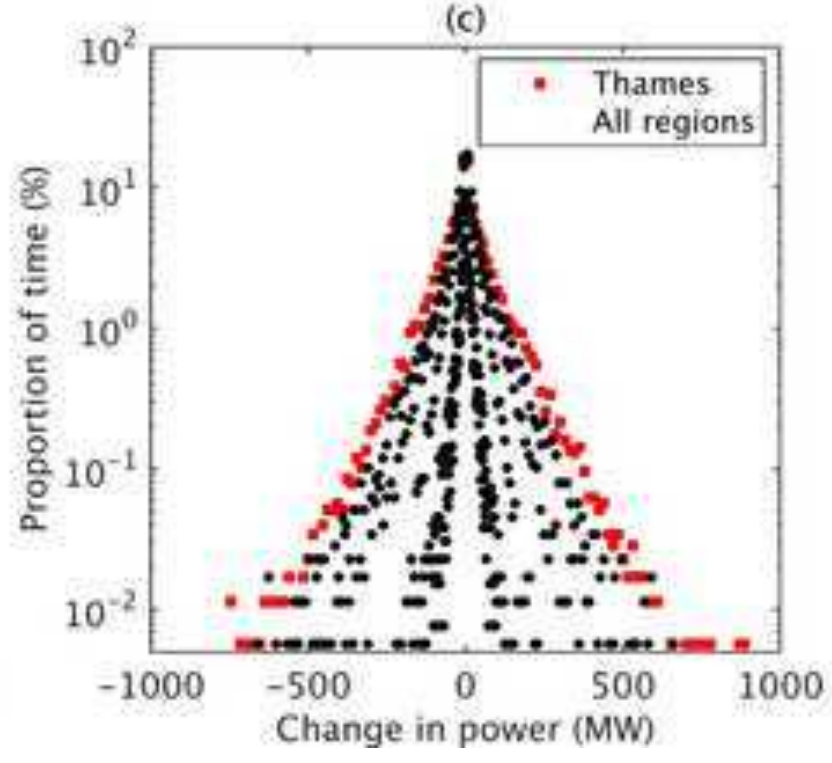


(a) Ramp-up events

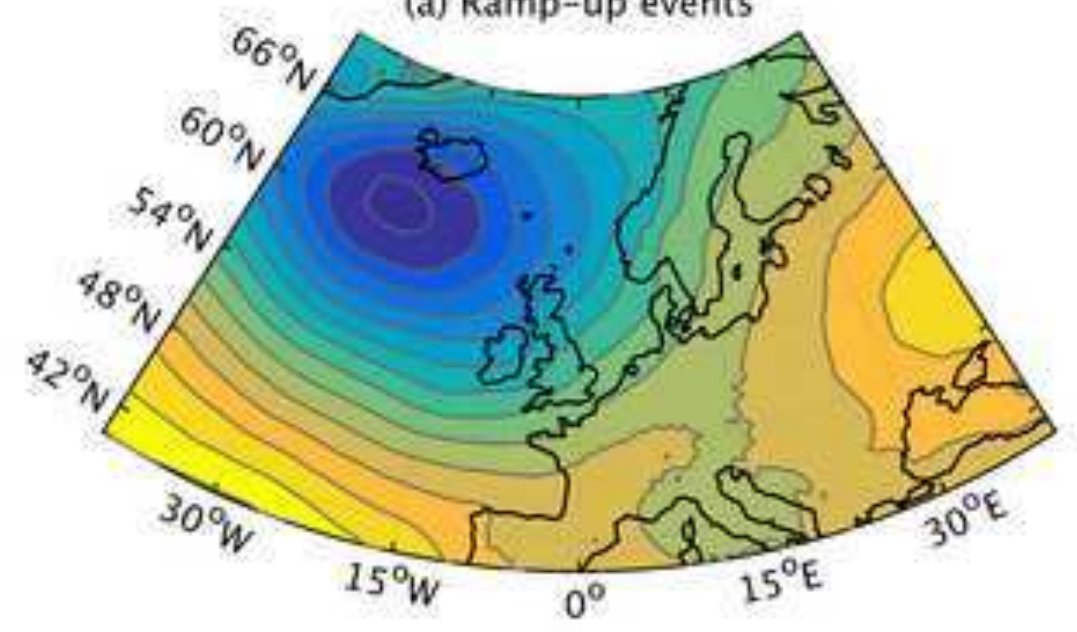

(b) Ramp-down events

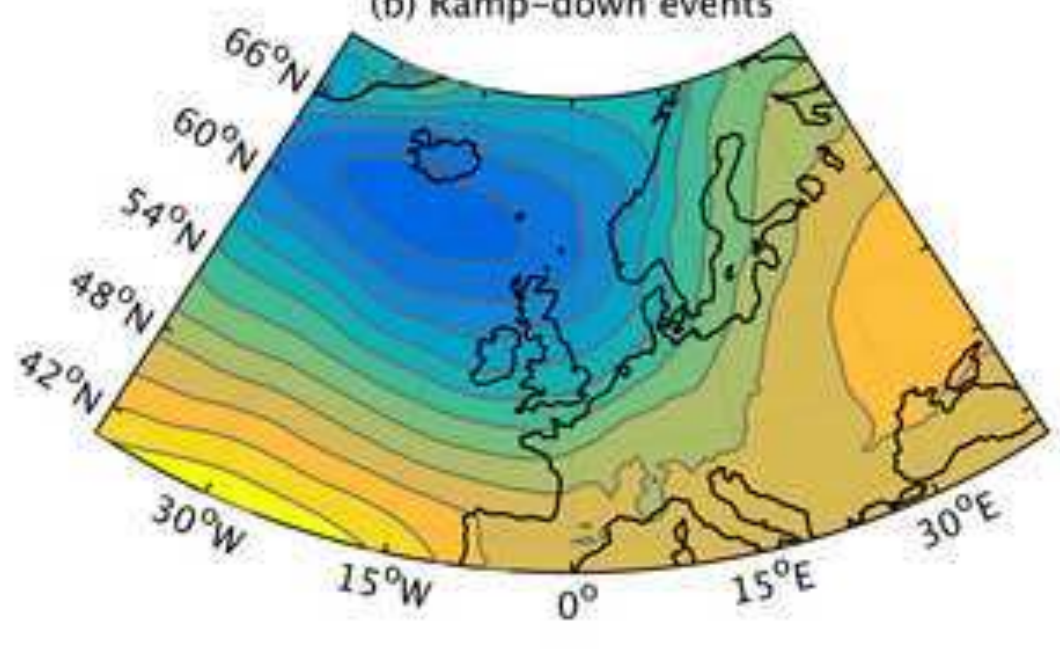

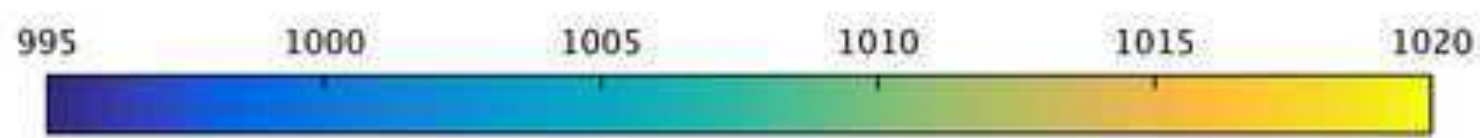

Surface pressure (hPa) 


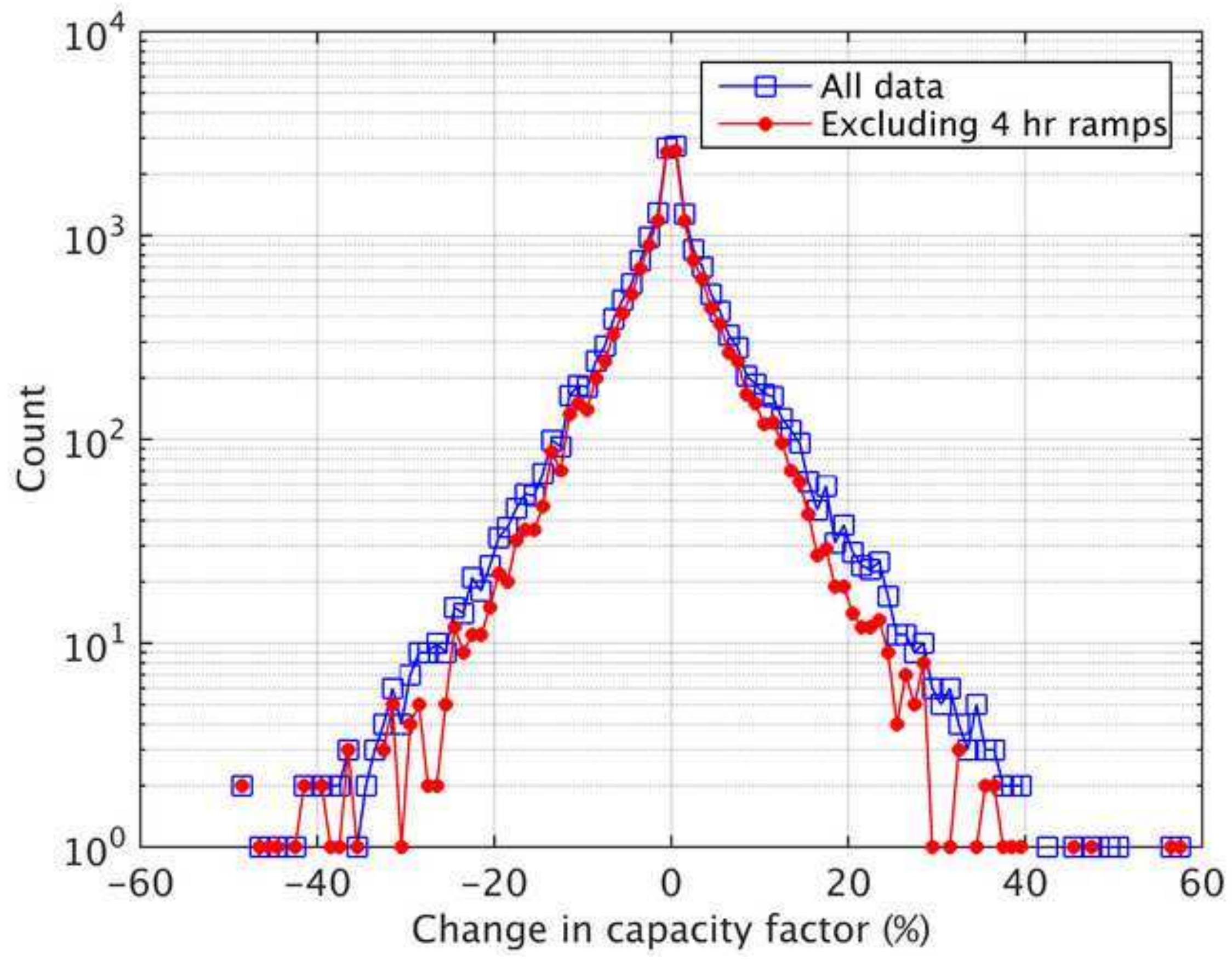


(a)

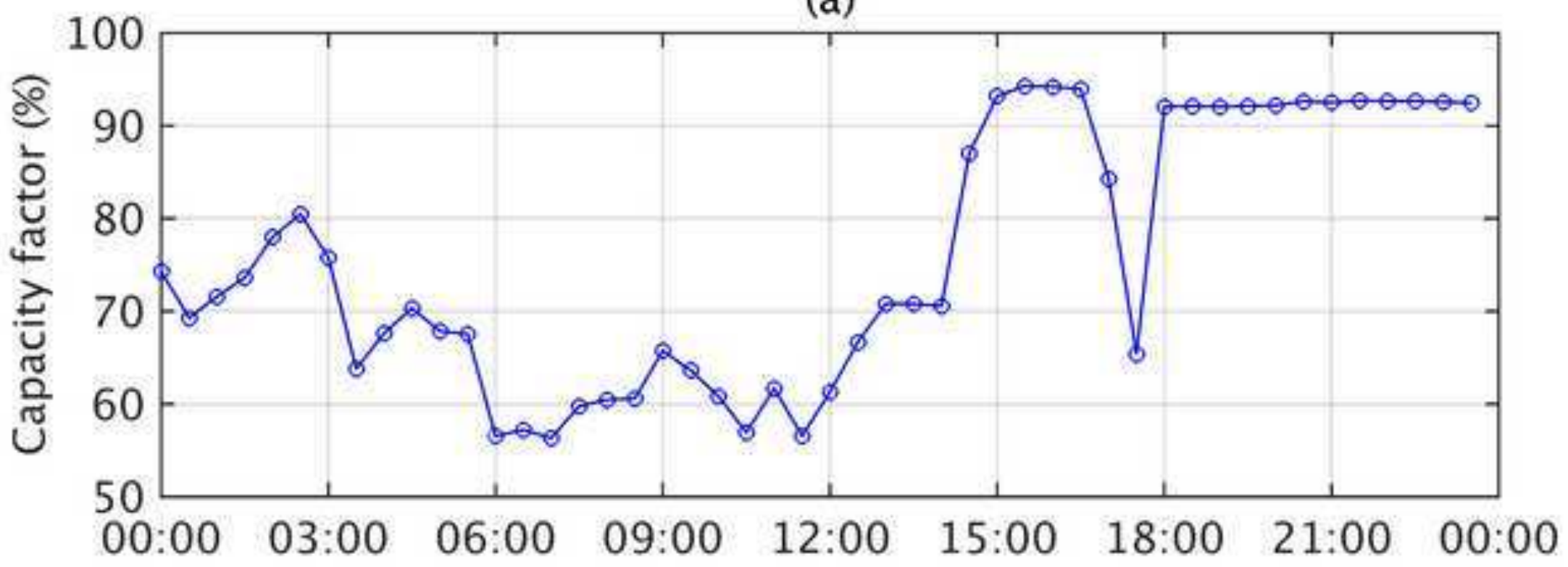

(b)

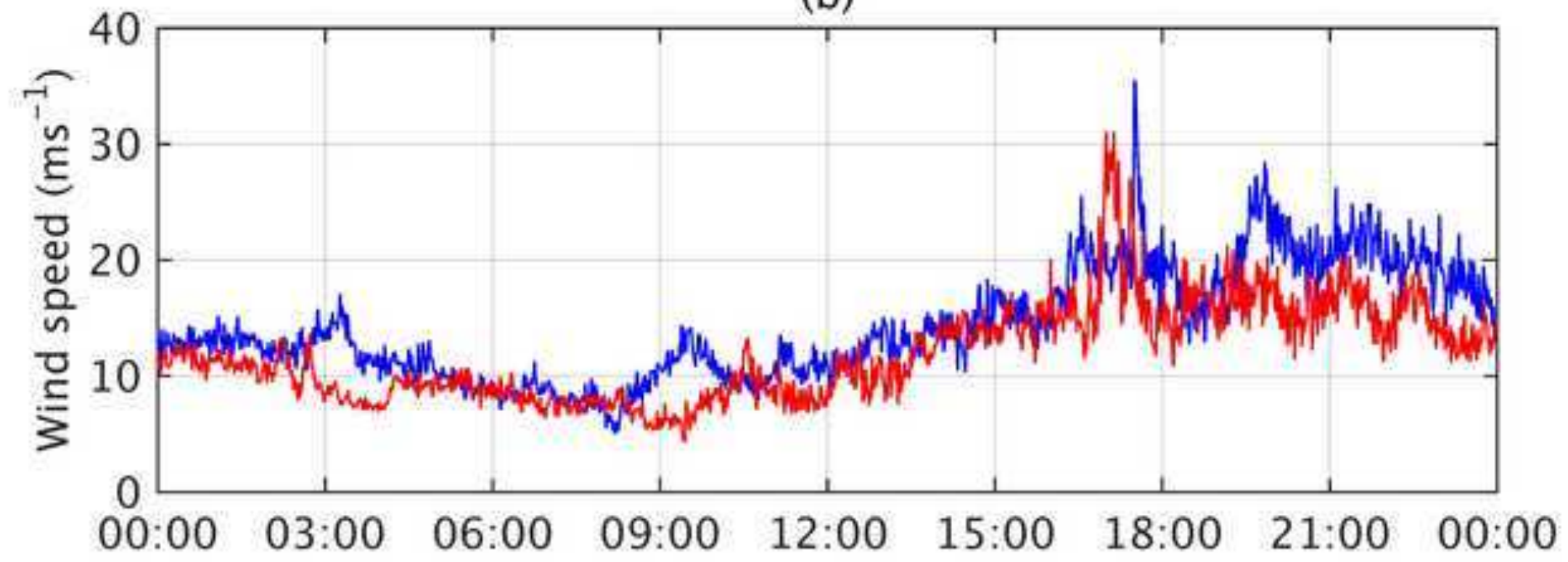


(a)

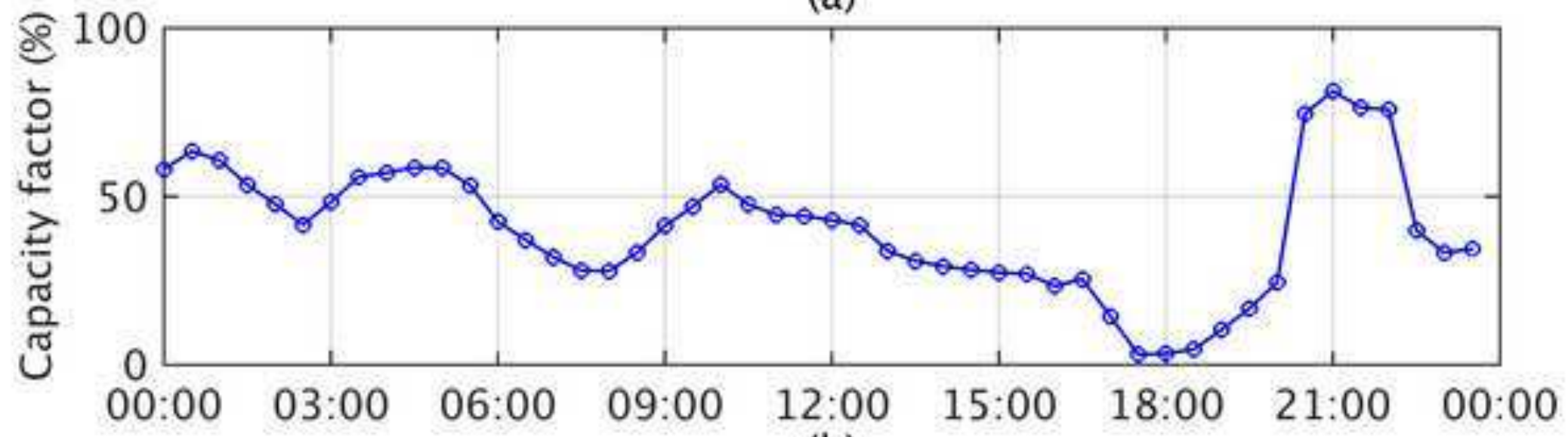

(b)

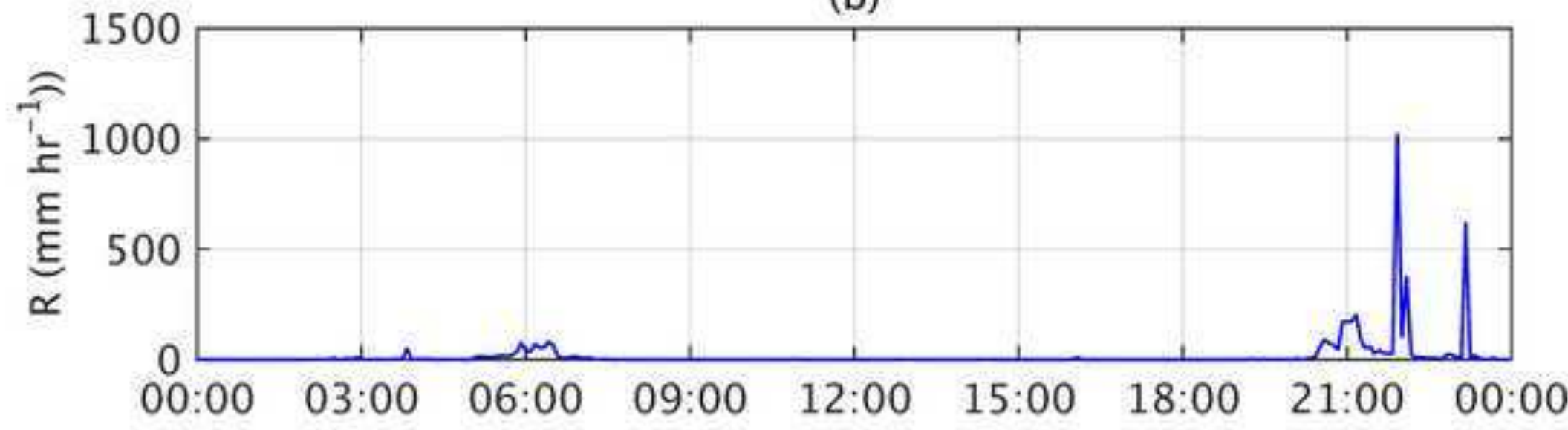

(c)

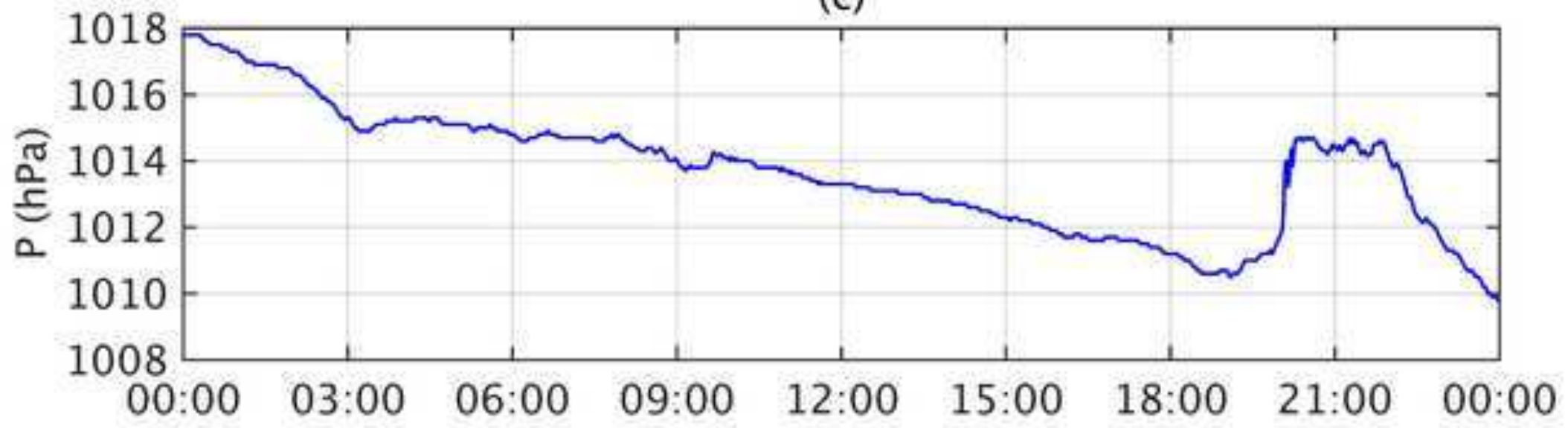


(a)

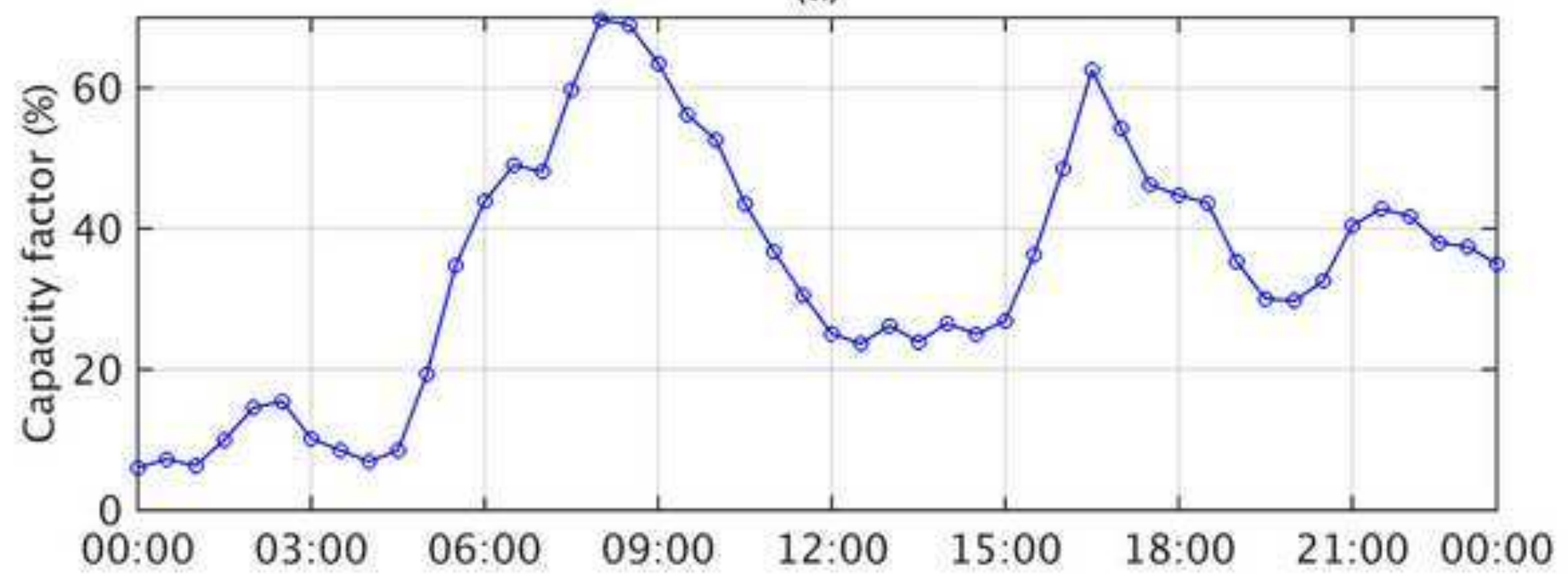

(b)

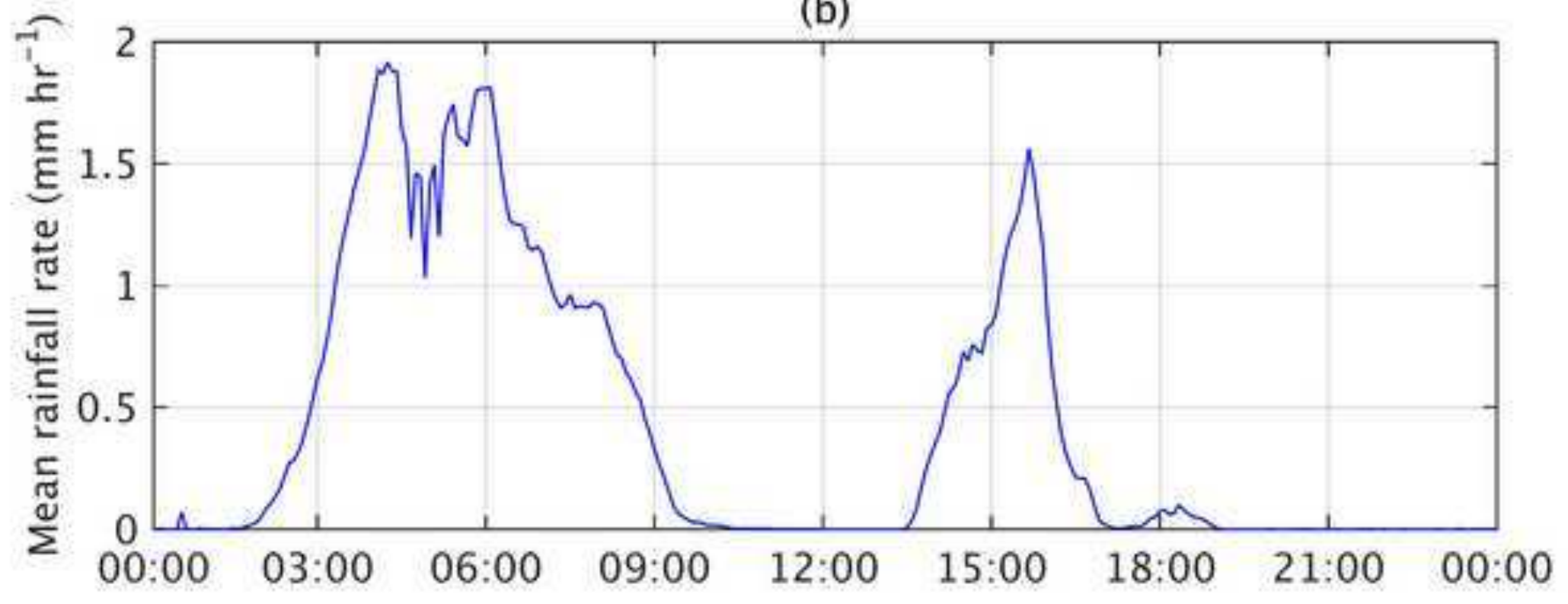


Click here to download high resolution image

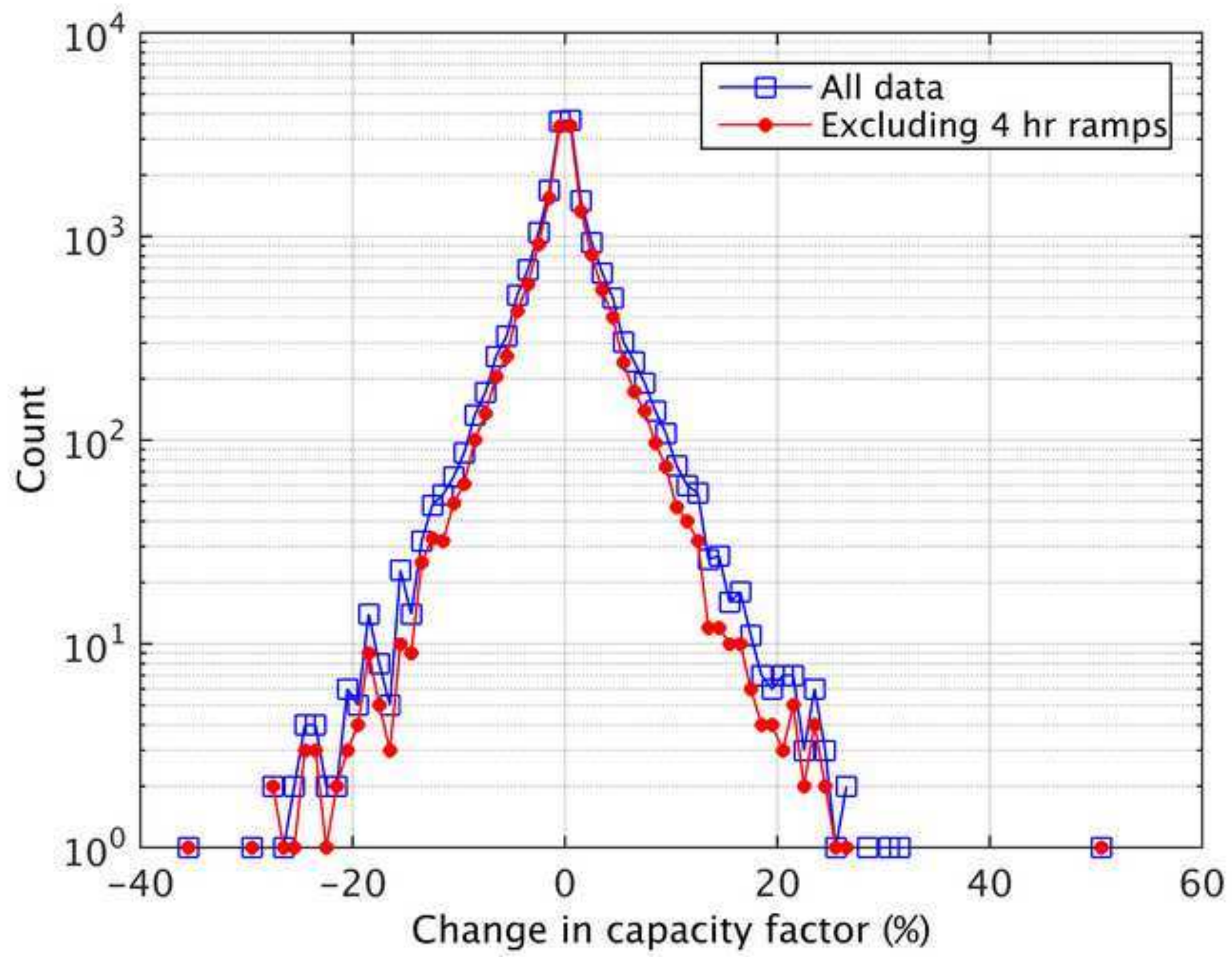

